See discussions, stats, and author profiles for this publication at: https://www.researchgate.net/publication/304859070

\title{
Theatre of Dissent: the Historical Imagination of the Irish Workers' Dramatic
} Company

Chapter · January 2014

DOI: $10.1057 / 9781137362186 \_7$

\section{CITATIONS}

0

1 author:

(2)

Lauren Arrington

National University of Ireland, Maynooth

30 PUBLICATIONS 28 CITATIONS

SEE PROFILE

Some of the authors of this publication are also working on these related projects:

Project Suffrage, Socialism, Revolution View project

Project Censorship View project
READS

49 


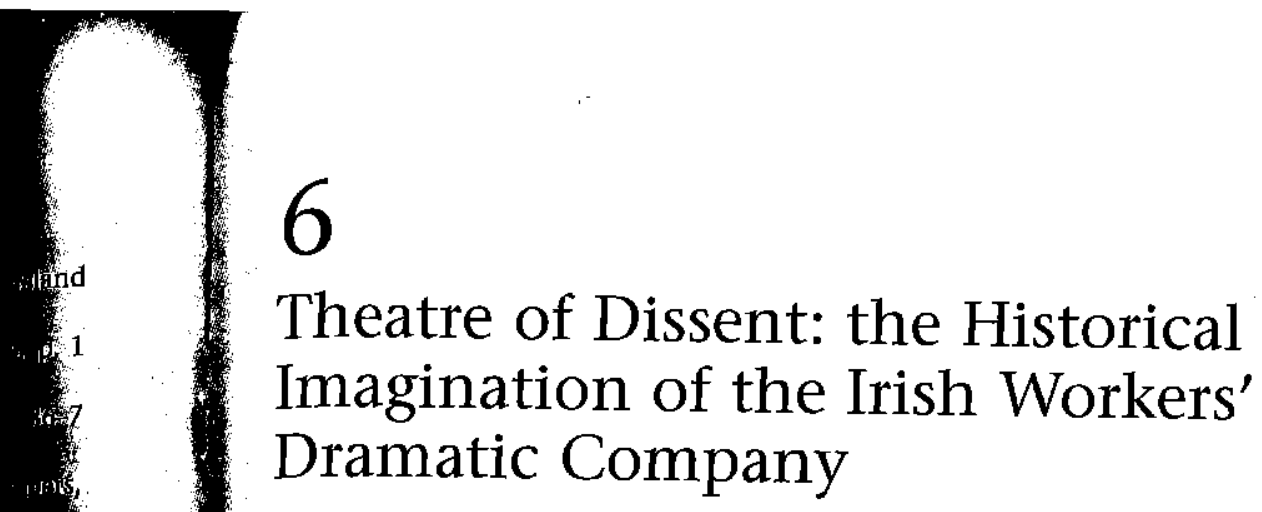

\section{Lauren Arrington}

While the dominant theatre of the Irish Literary Revival relied on ahistorical mythologies to imagine a unified (and arguably Unionized) nation, the Irish Workers' Dramatic Company was intent on a drama of disruption. ${ }^{1}$ Based at Liberty Hall, the headquarters of the Irish Transport and General Workers' Union, and concerned with the material welfare of the working classes, the amateur company presents an alternative to the preoccupations of the Abbey Theatre with its mystical depictions of an uncorrupted west, representations of an imaginary peasantry and its concern with nationality. Whereas the aim of Yeats and Gregory was to represent the nation in plays dealing with Irish legend or 'Irish historic personages or events', the Irish Workers' Dramatic Company aimed to intervene in the present moment, to reimagine the place of the individual in history and in the process to effect material change. ${ }^{2}$

The Irish Workers' Dramatic Company (IWDC) was established in June 1912 by Delia Larkin, sister to the labour leader and founder of the Irish Transport and General Workers' Union (ITGWU), Big Jim. Prior to the costly Lockout of 1913, the ITGWU had the resources to invest in cultural enterprises. Delia Larkin began by organizing a workers' choir and a workers' band, and the popularity of these pursuits inspired her to organize an amateur dramatic club. The choir, the band and the dramatic club served several functions. They offered free, edifying entertainment for the workers in the evenings, with rehearsals providing an alternative to the public house. The clubs were only open to members of the ITGWU or the Irish Women Workers' Union (a subset of the ITGWU) and served as a way to increase union membership, since interested parties would have to join the union if they wished to take part. Furthermore, the performative aspects of the clubs served to propagandize the values and objectives of the union. In addition to this 


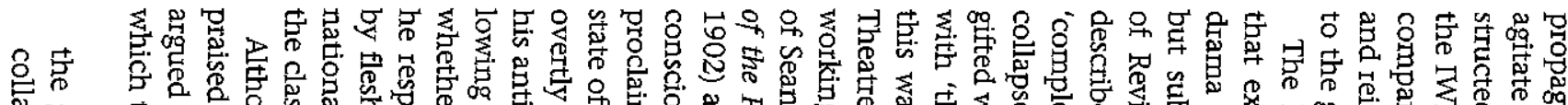

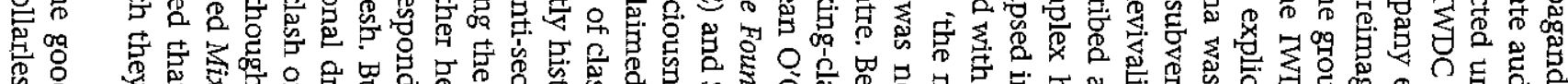

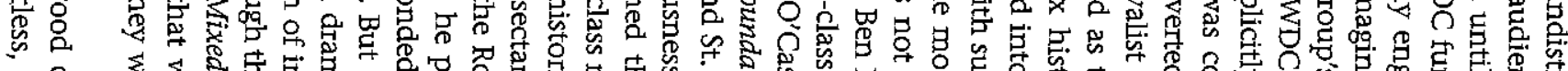

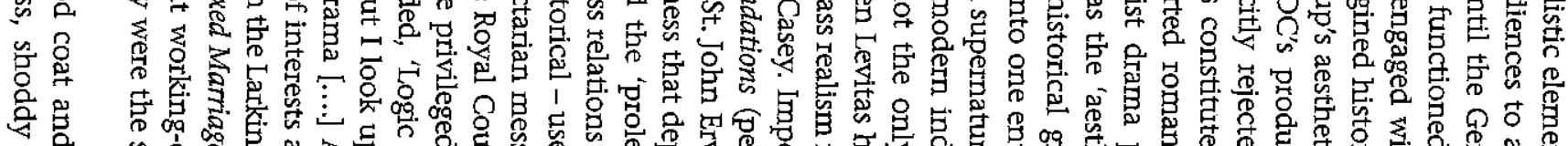

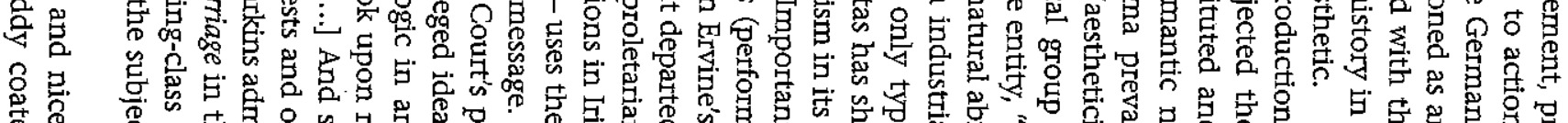

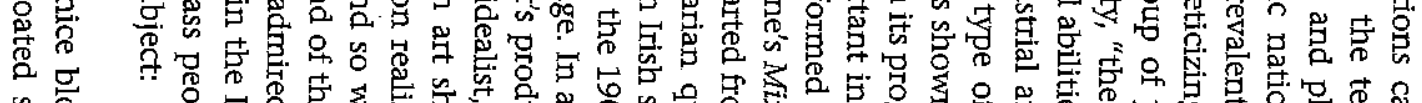

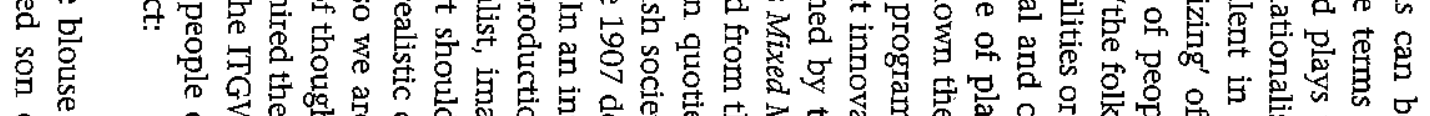

옹은

宫 芦.

옹

容兽

鱼参

бु

总罂.

苋

鱼坴

拿克

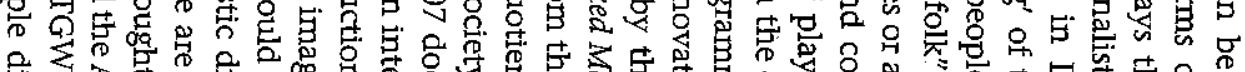

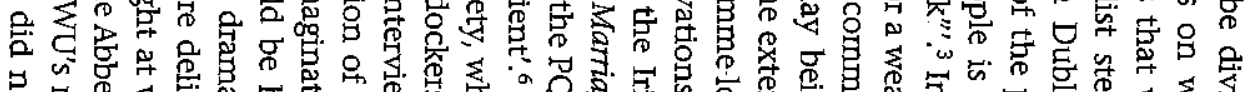

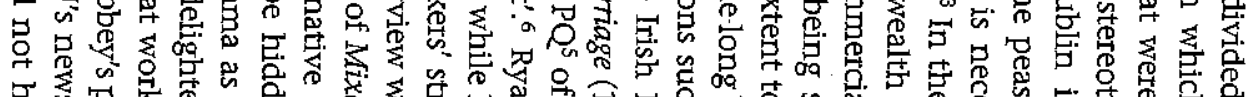

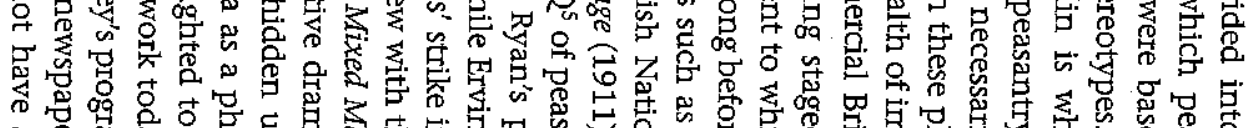

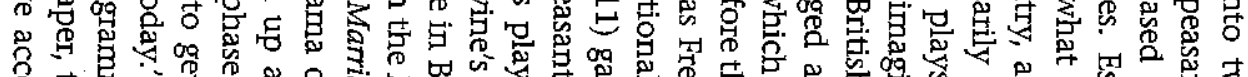

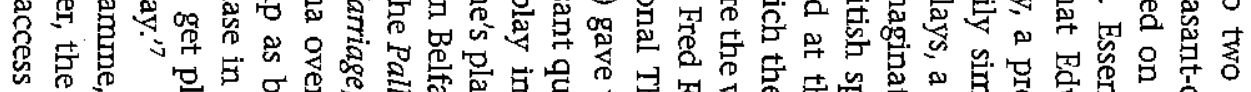

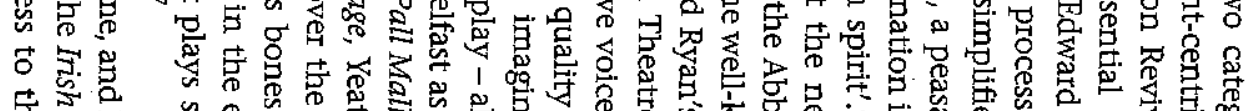

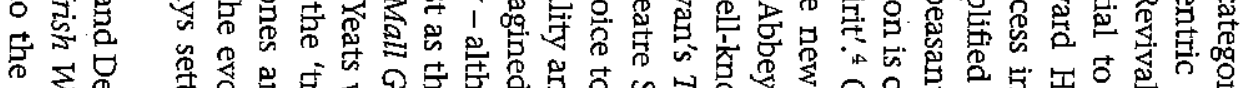

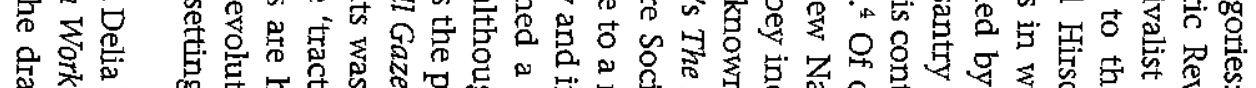

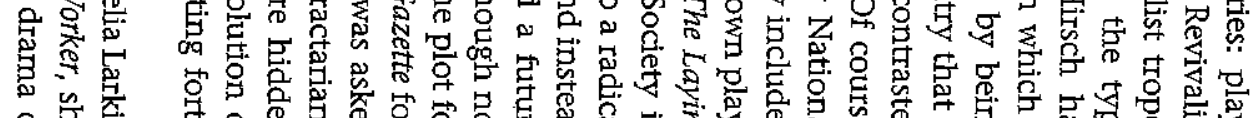

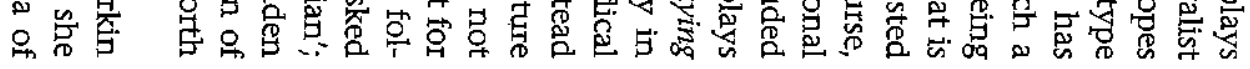

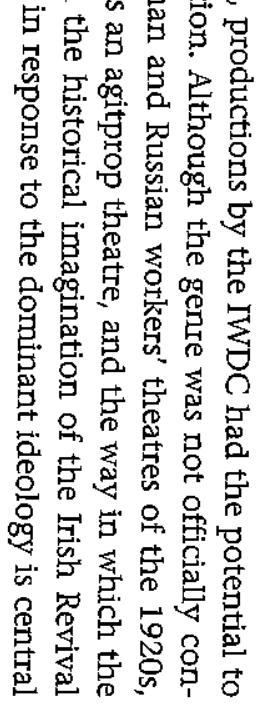

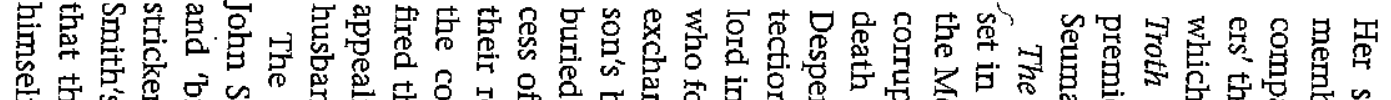

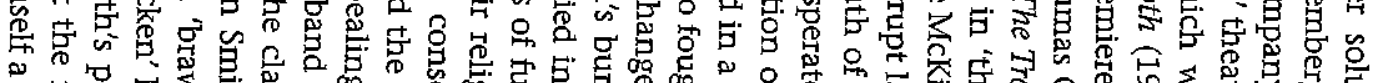

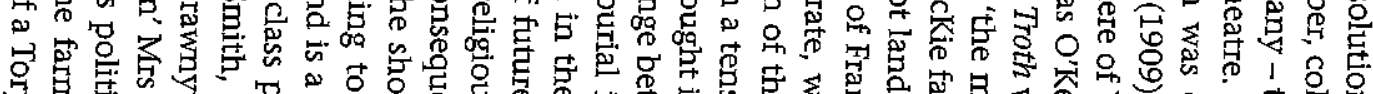

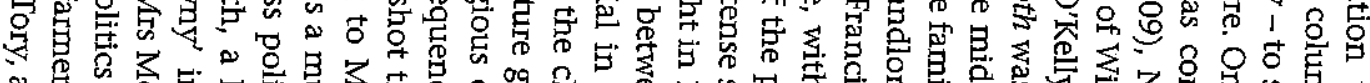

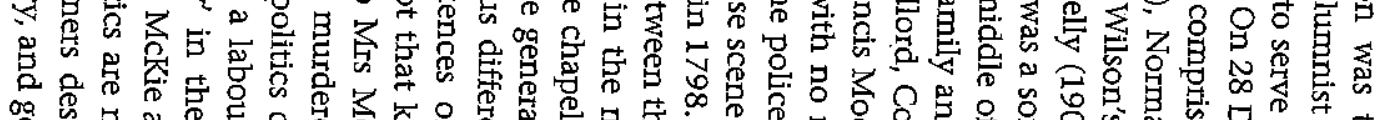

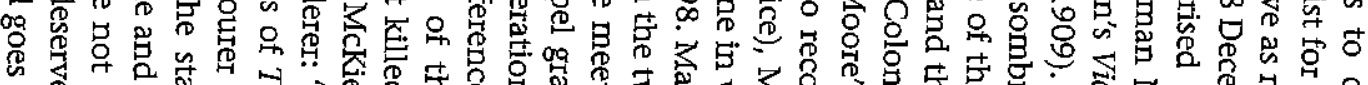

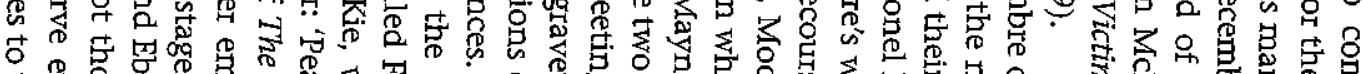

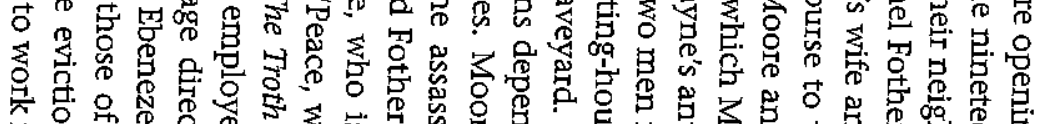

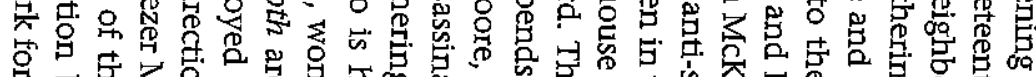

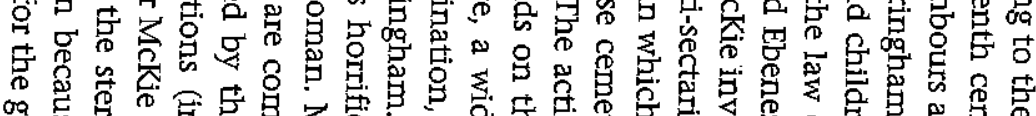

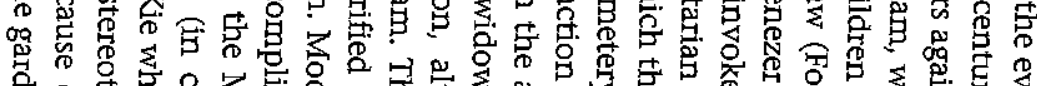

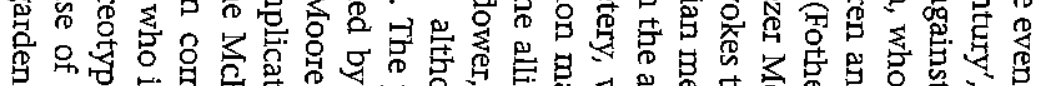

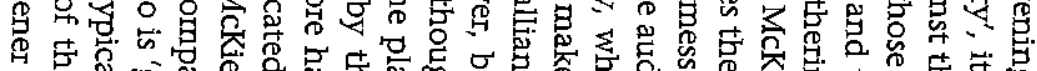

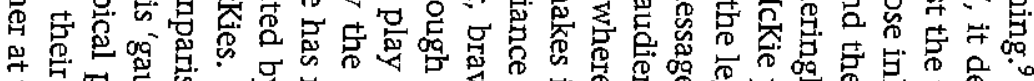

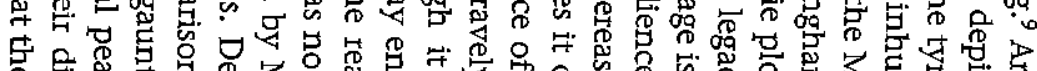

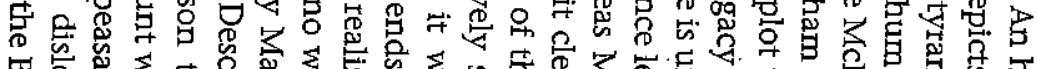

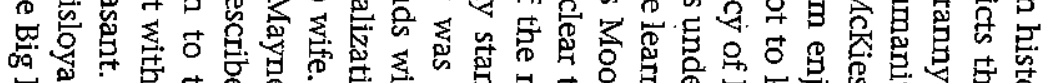

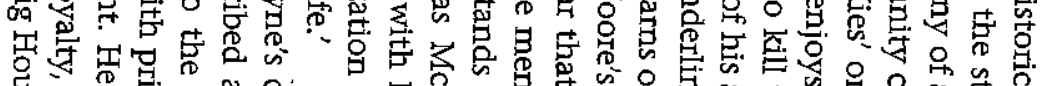

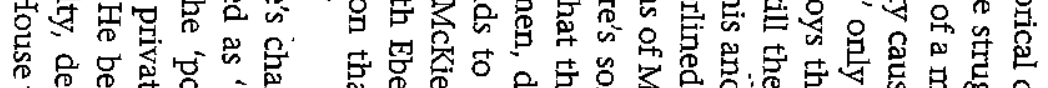

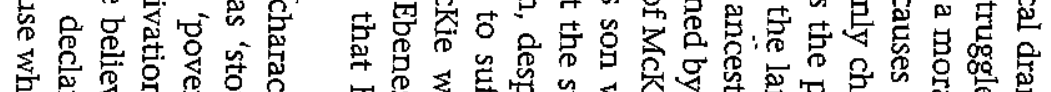

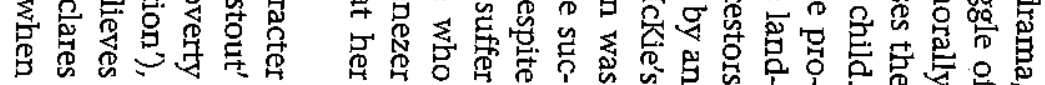

इ중

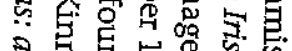

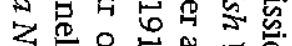

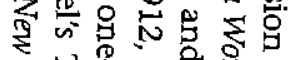

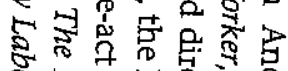

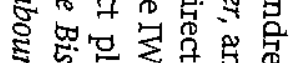

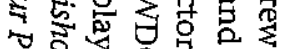

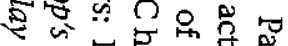

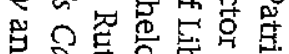

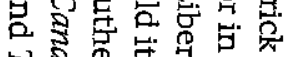

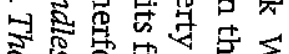

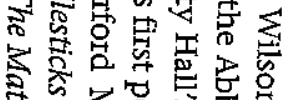

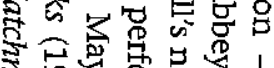

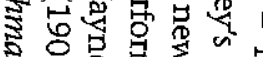

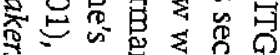

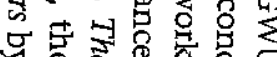

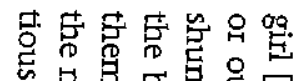

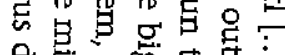

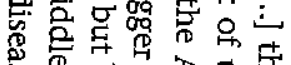

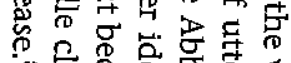

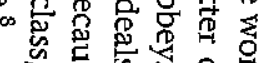

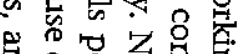
虽另宫宫

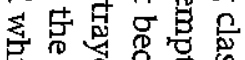

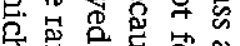

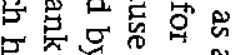

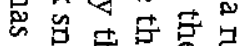

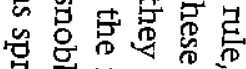
惫药吕品

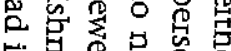

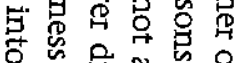

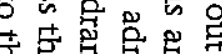

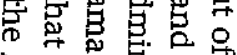

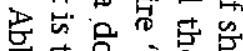

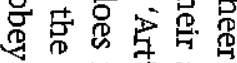

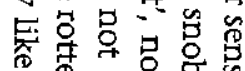

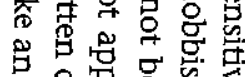

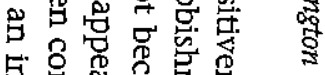

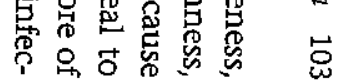




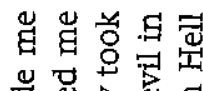

密客穿

द्व

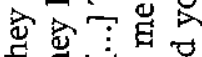

声主焉

营票总密

要焉

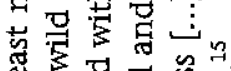

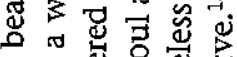

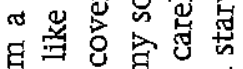

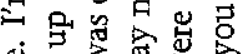

岁总芯

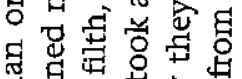

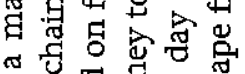

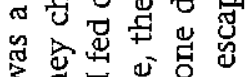

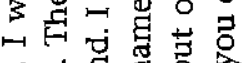

बं

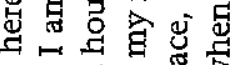

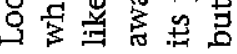

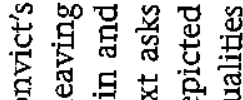

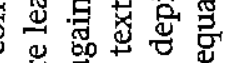
ฐ

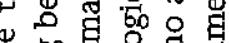

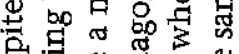

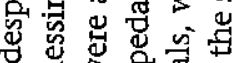

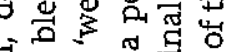

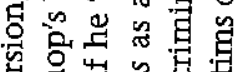
尊要出它 要

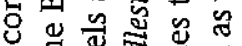
๙

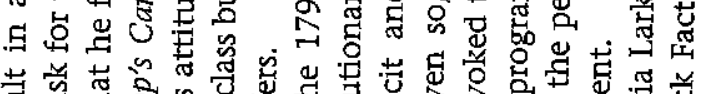

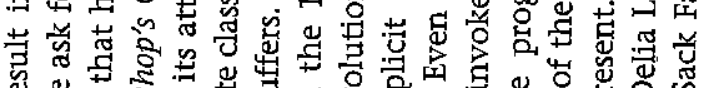

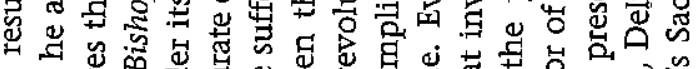

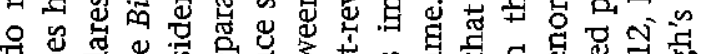

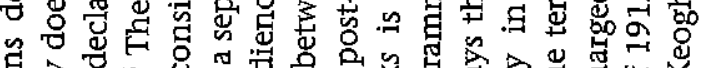

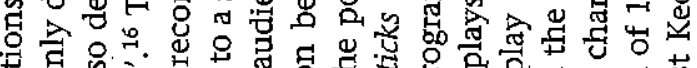

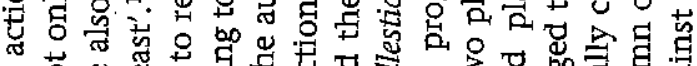

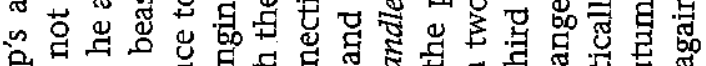

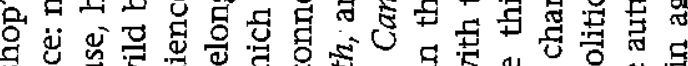

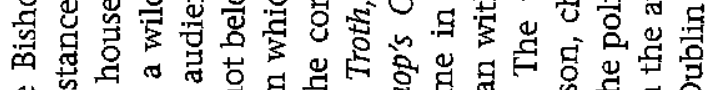

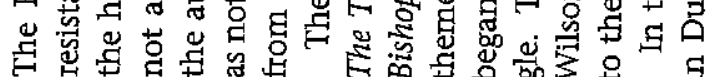

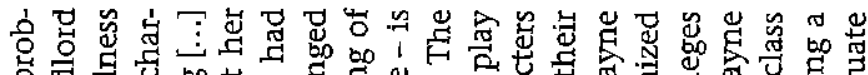

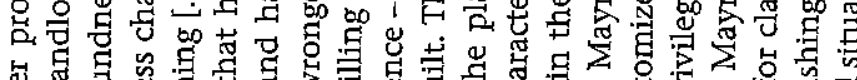

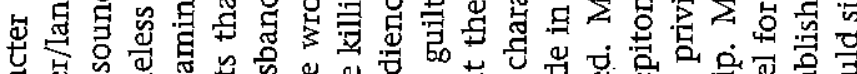

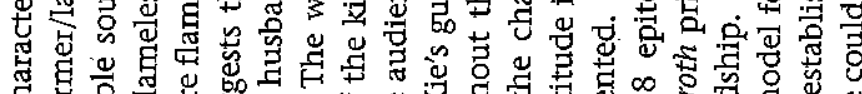

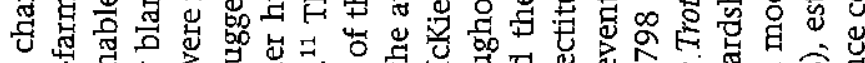

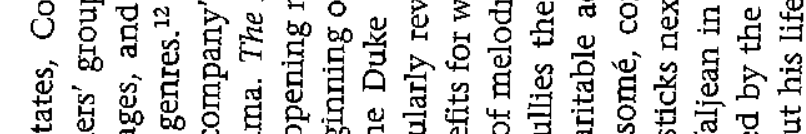

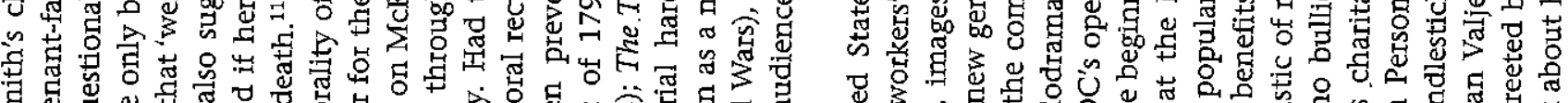

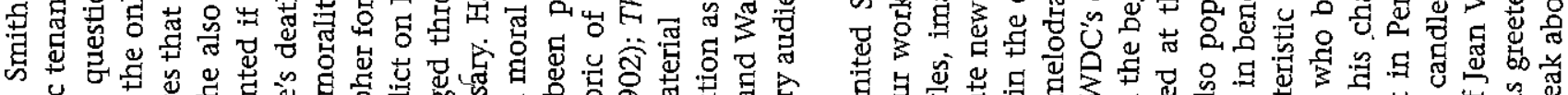

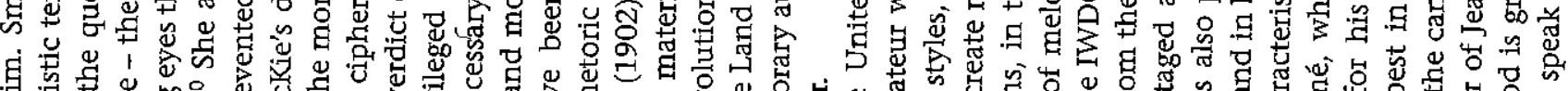

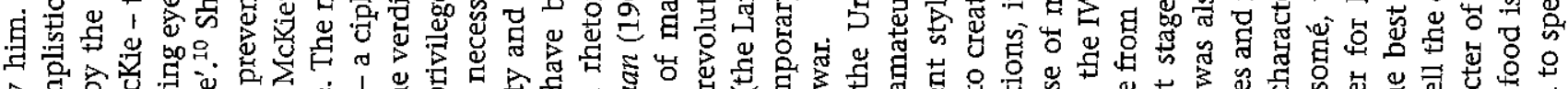

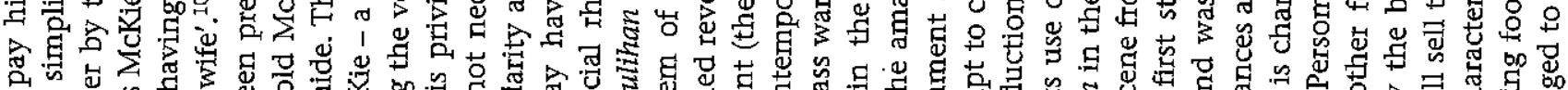

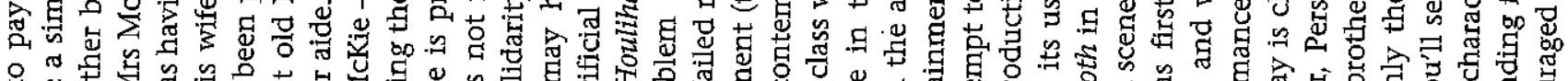

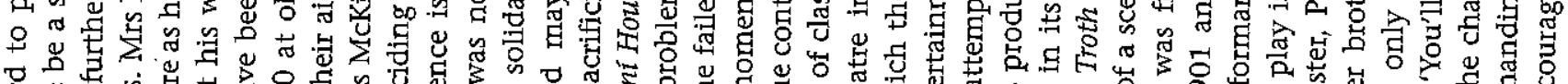

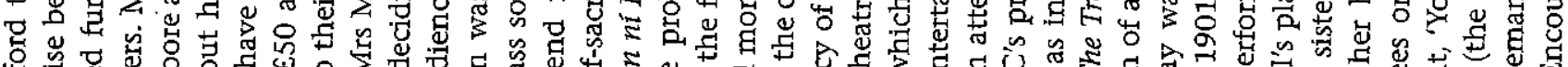

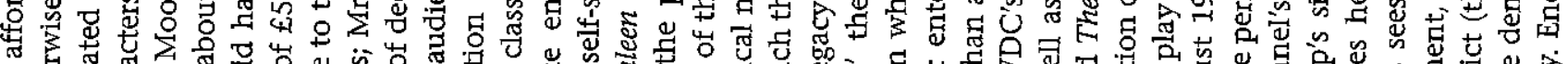

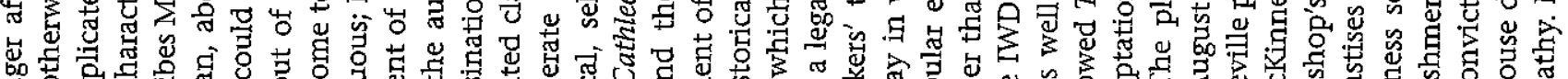

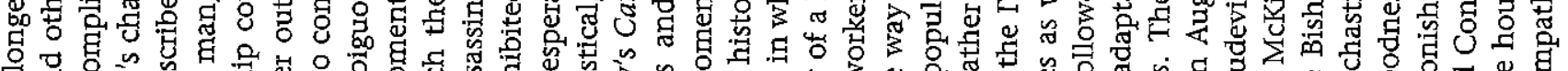

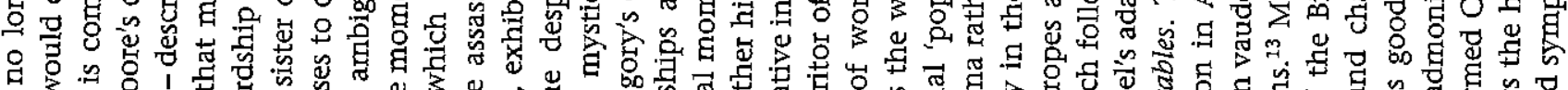
G

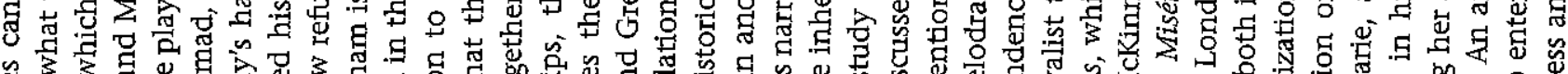

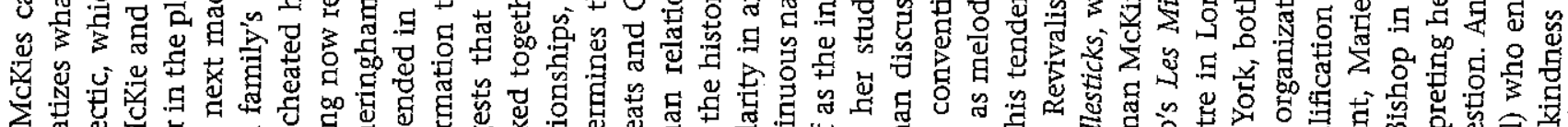

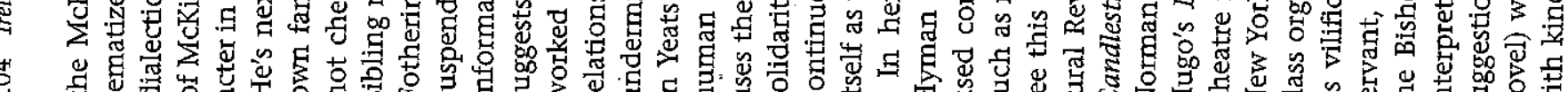

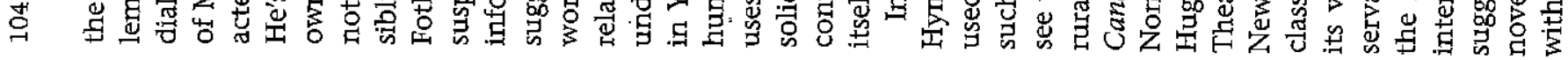




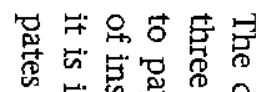

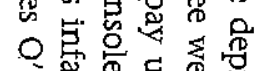

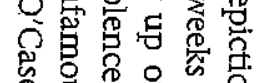

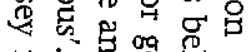

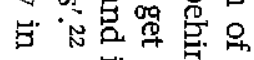

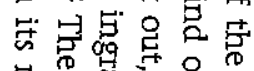

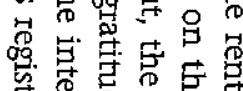

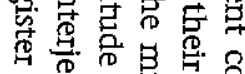
可

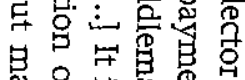

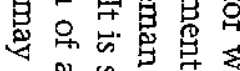

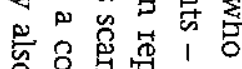

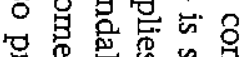

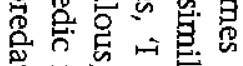

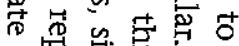

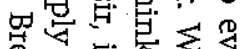

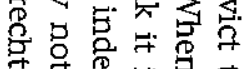

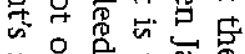
台量要要要

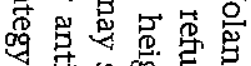
只鱼宫思

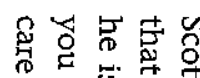

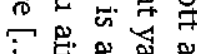
开昌昌昌 \%

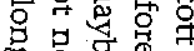
N覀占员 至它宫 政 당요 的骂曷

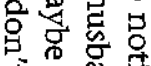
牙谓分 热

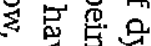
包星品

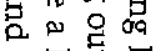
居䒯 ᄋ 年苍芯 总旁要

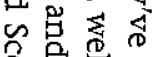
定空 을

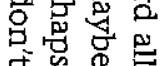

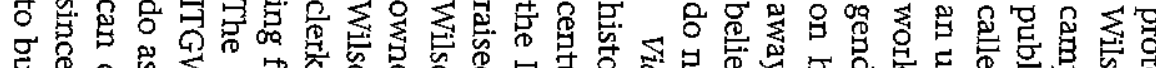

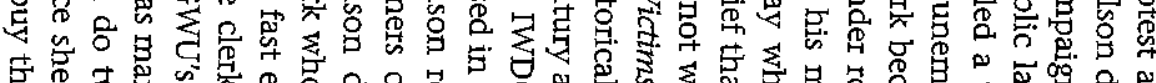

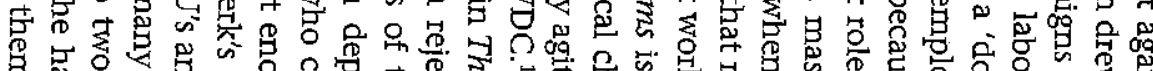

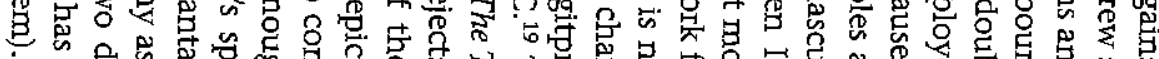

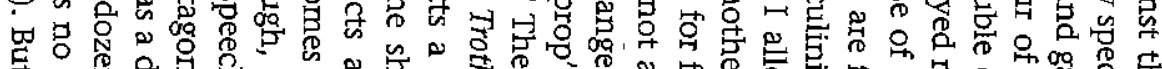

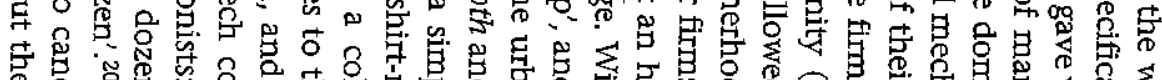

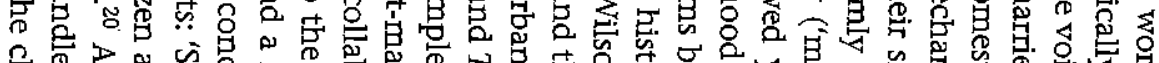

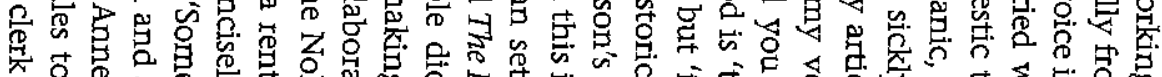

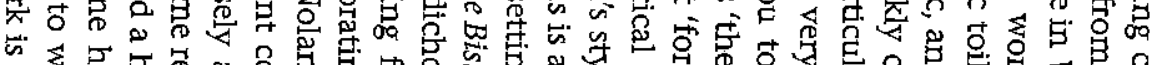

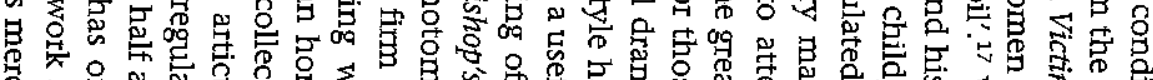

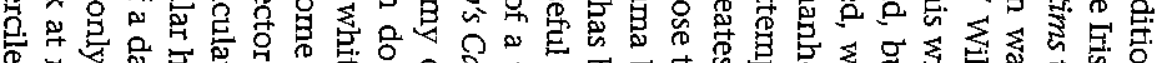

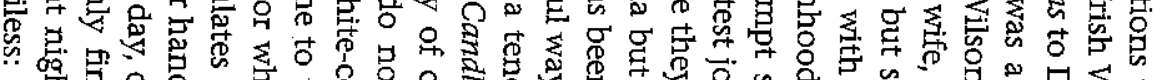

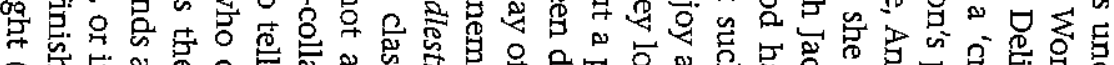

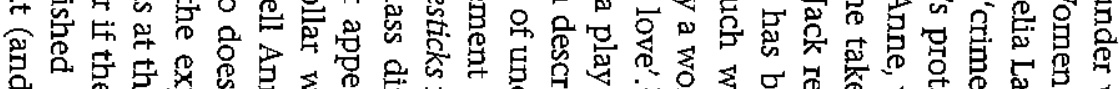

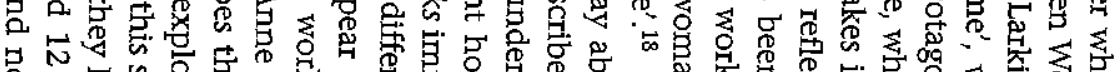

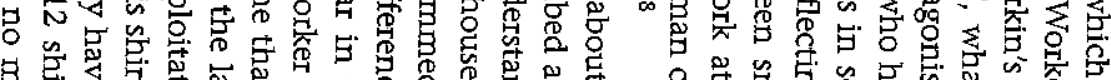

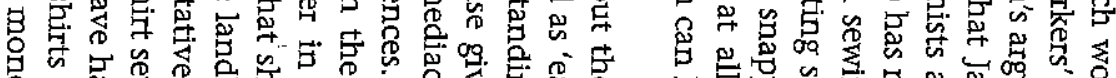

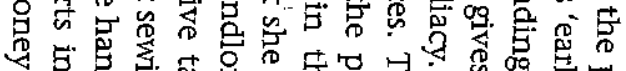

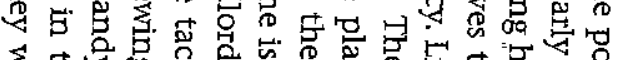

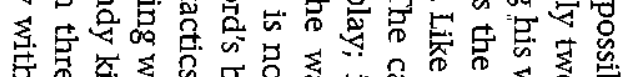

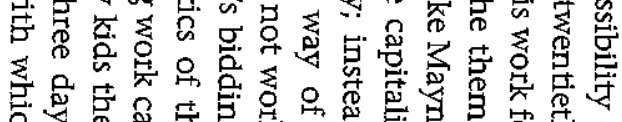

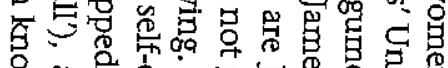

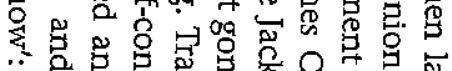

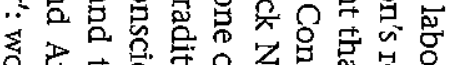

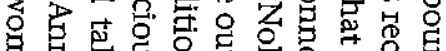

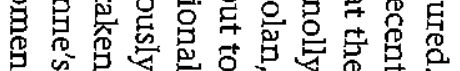

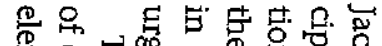

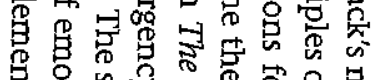

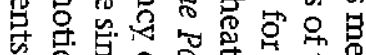
象总虽曷员宫

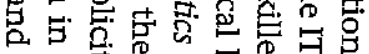

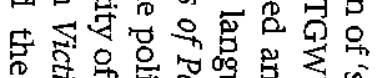

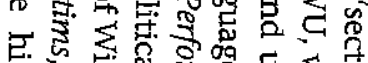

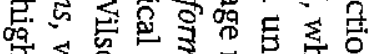

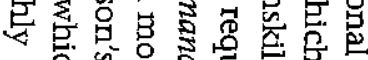

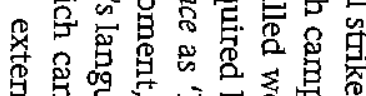

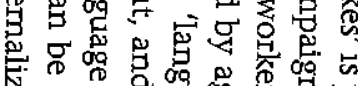

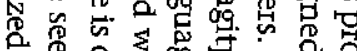

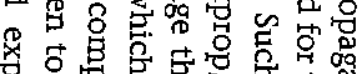

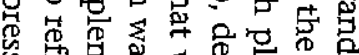

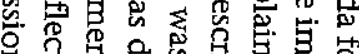

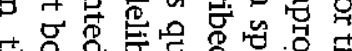

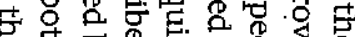

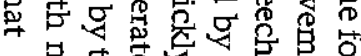

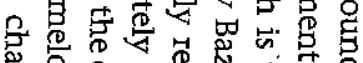

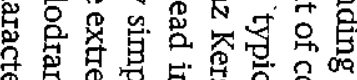

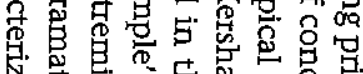

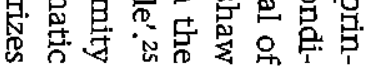

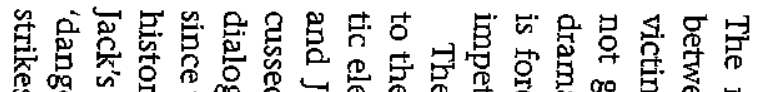
영응 웅

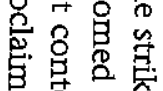

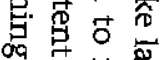

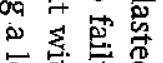
官富点 客范垈 总点宫

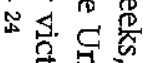
总是罟 芑宓蒙 哭昜员

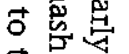

胥点 今管 点点学

综

量酎品 心㕝㫷 密空 员罂

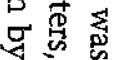

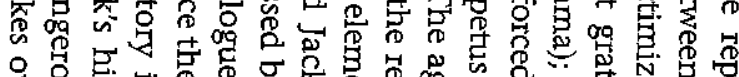

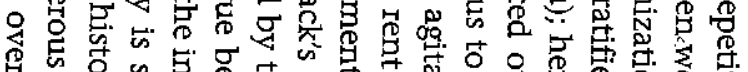

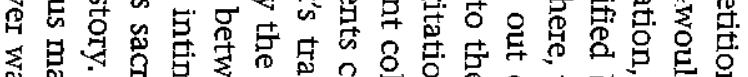

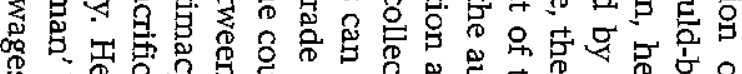

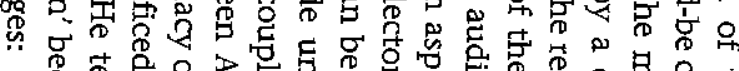

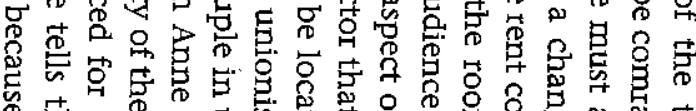

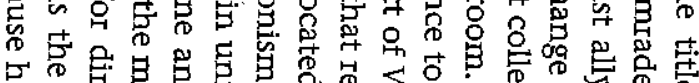

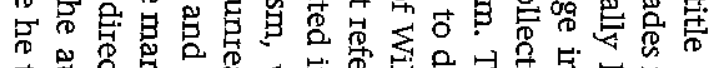

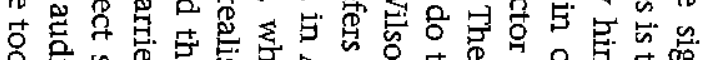

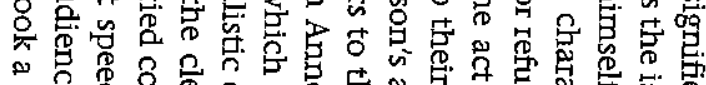

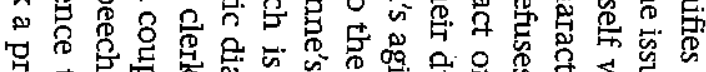

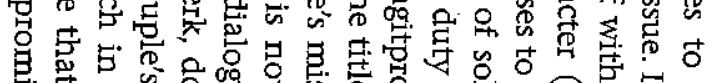

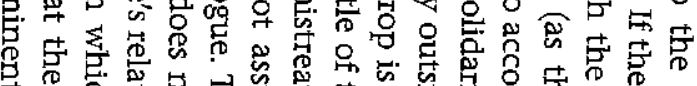

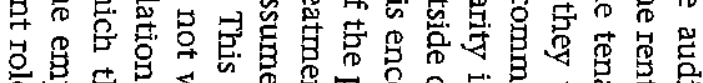

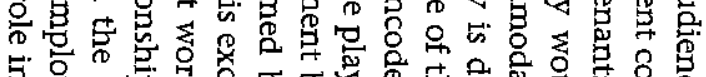

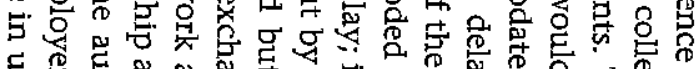

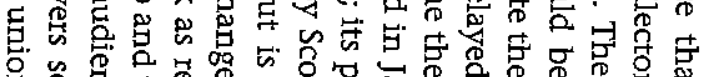

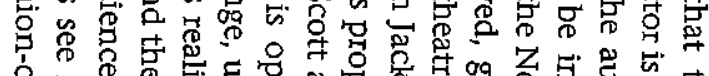

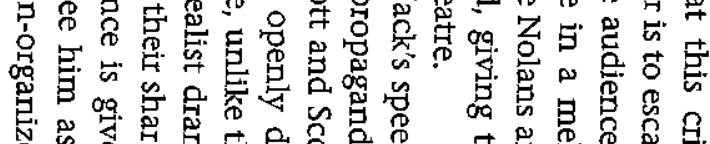

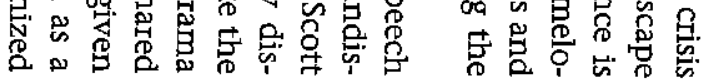

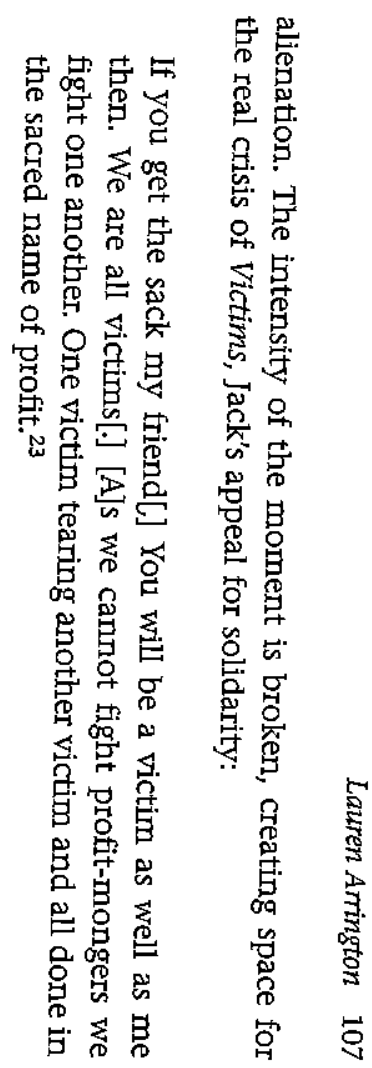




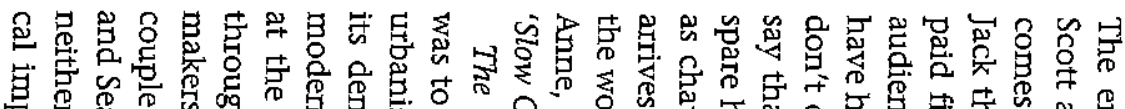

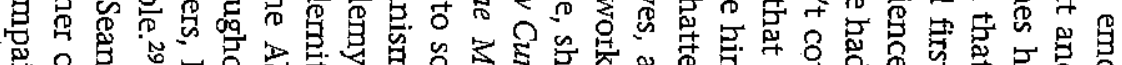

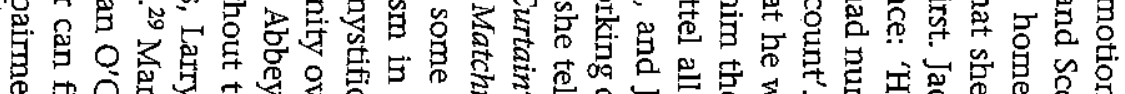

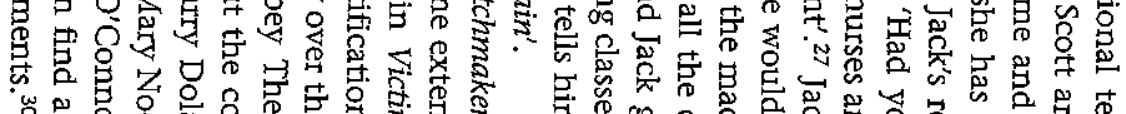

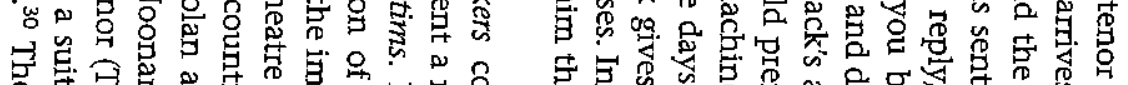

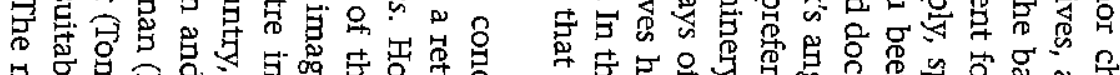

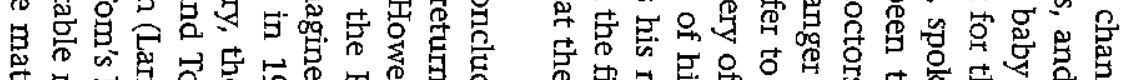

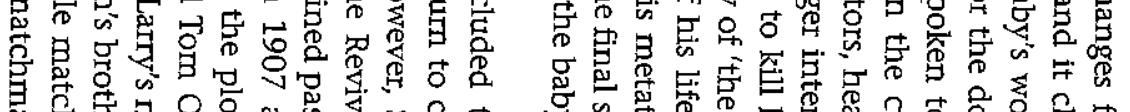

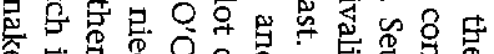

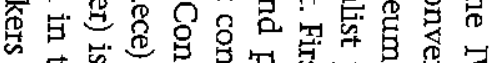

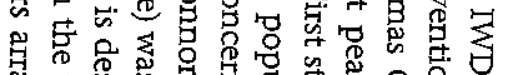

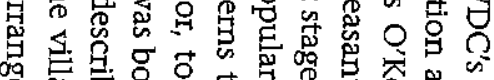

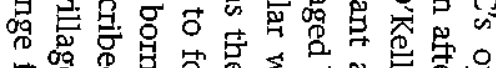

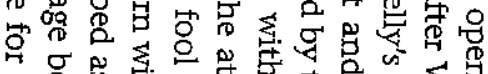

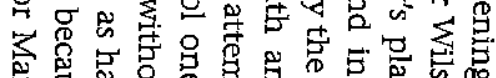

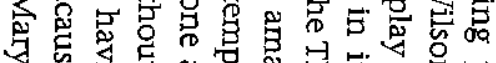

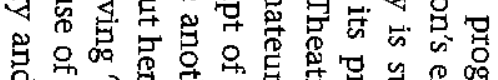

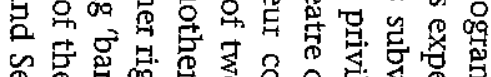

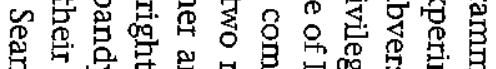

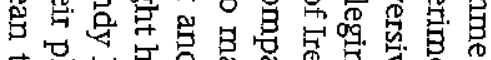

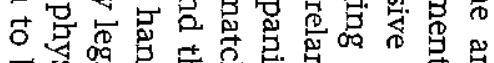

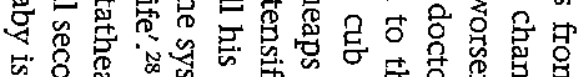

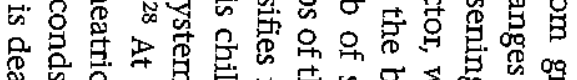

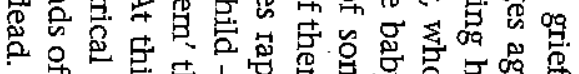

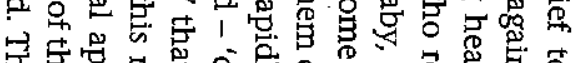

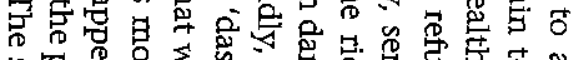

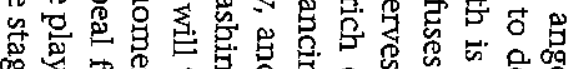

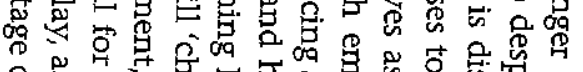

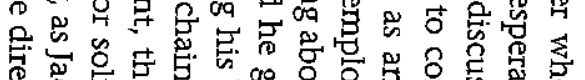

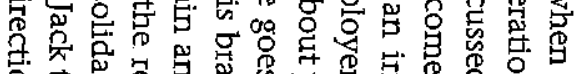

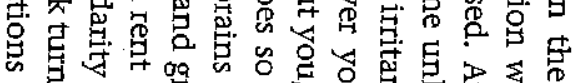

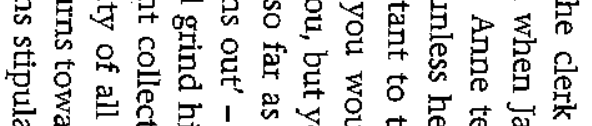

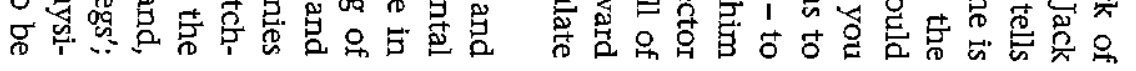

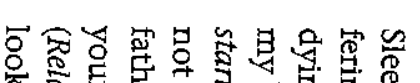

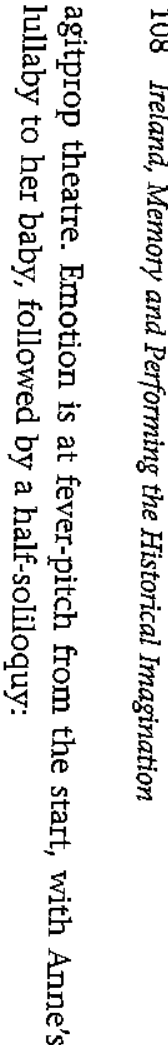

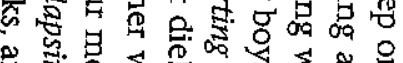

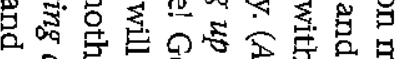

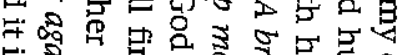

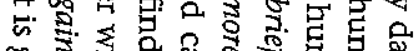
要.

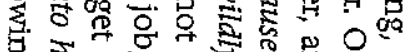

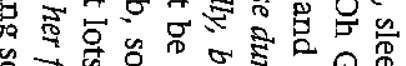

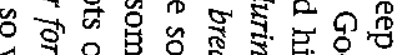

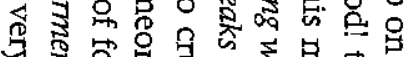

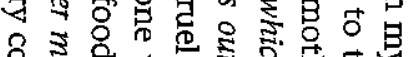

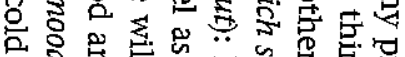

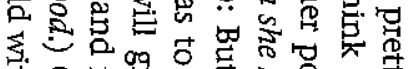

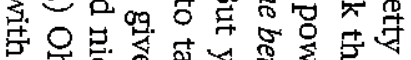

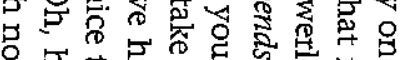

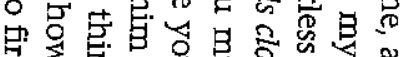

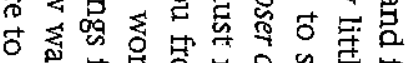

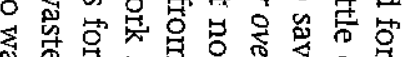

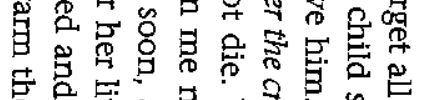

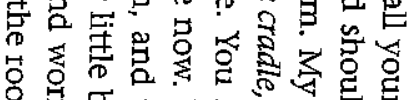
桴

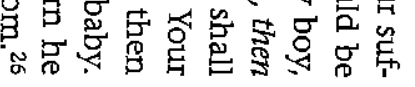

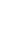
(n) (1) 然 


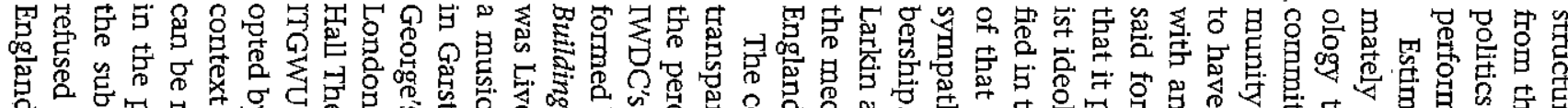

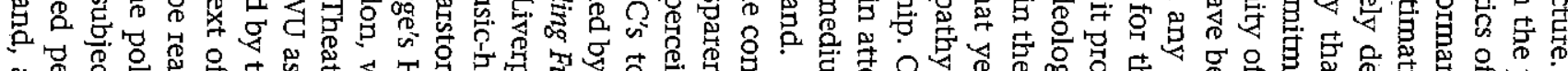

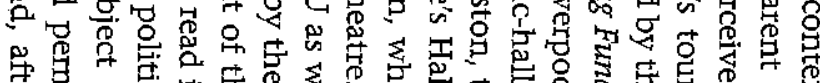

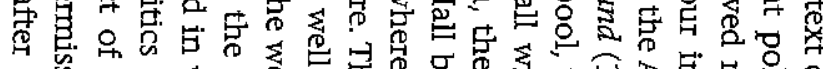

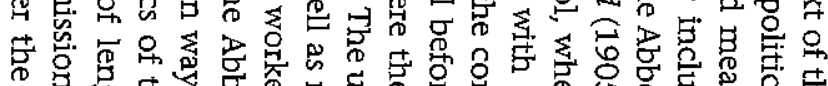

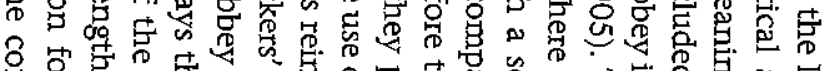

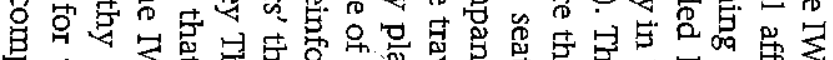

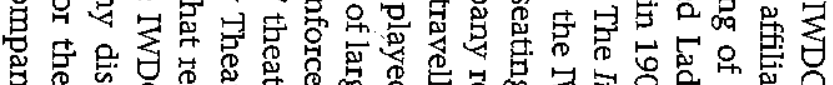

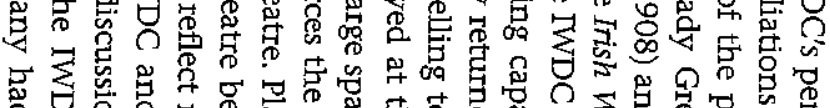

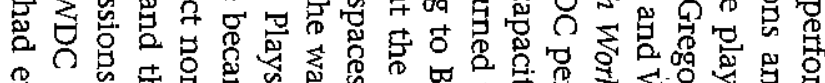

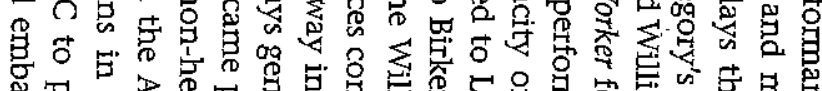

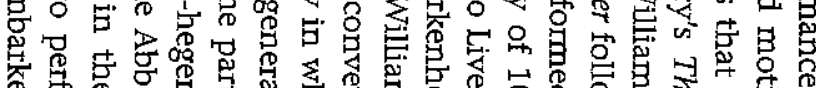

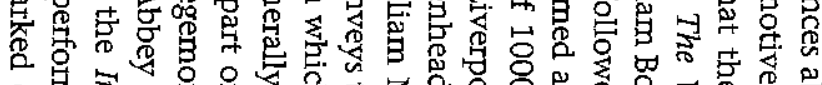

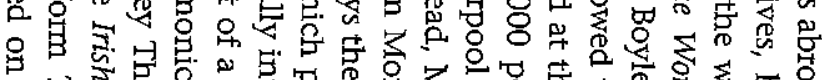

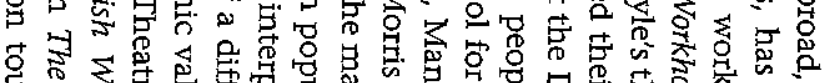

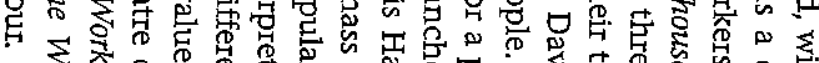

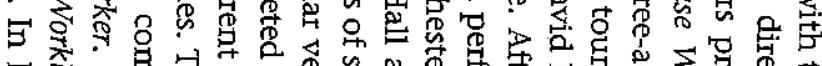

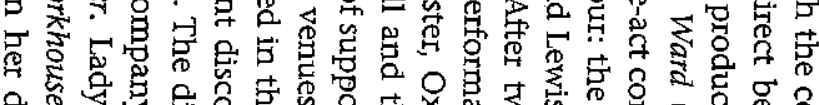

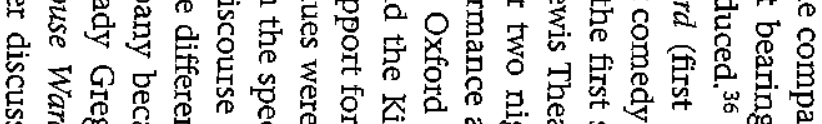

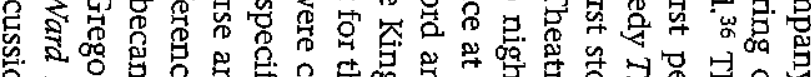

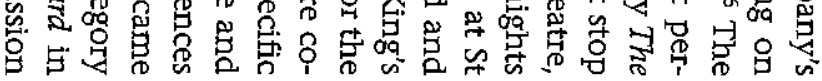

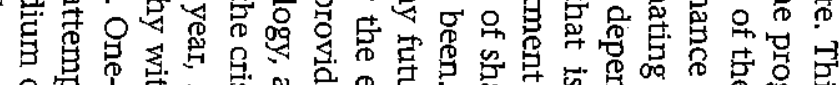

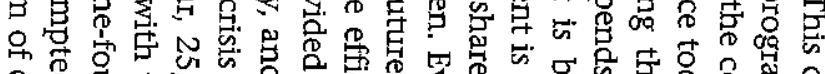

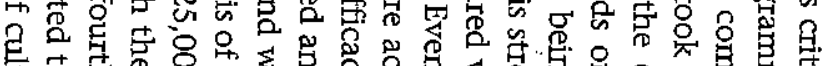

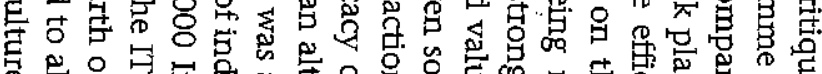

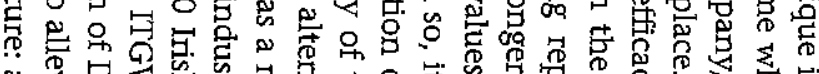

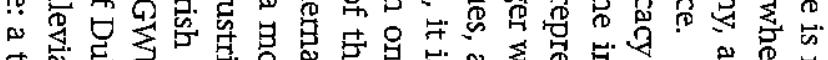

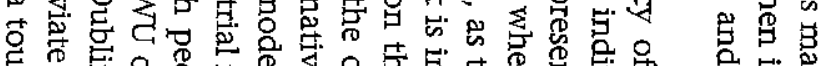

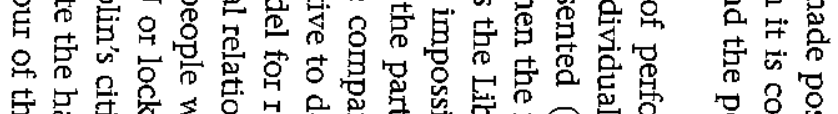

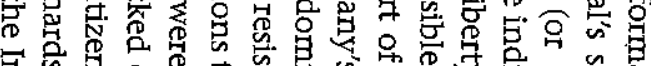

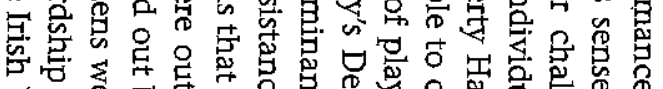

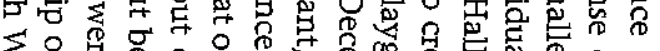

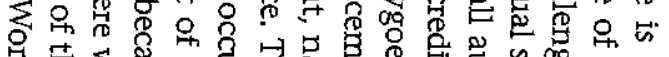

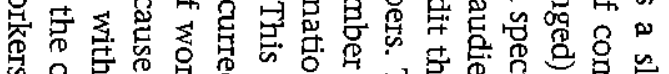

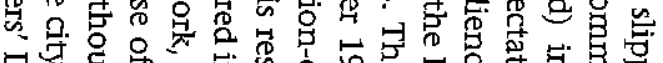

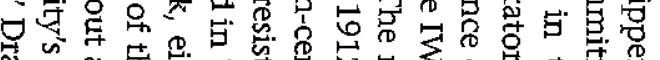

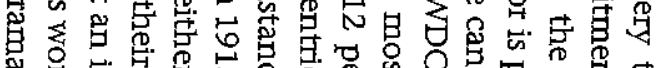

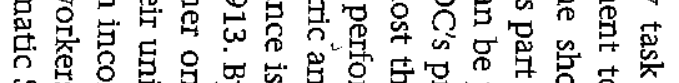

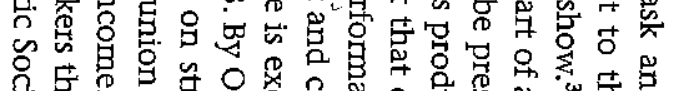

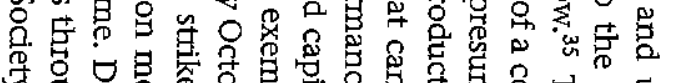

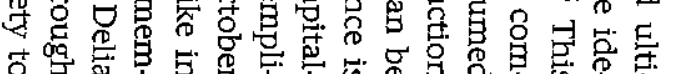

范 觜 要 곤 2

然总总

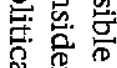
實管啹 象

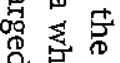
م园 政 宫官 芦究落 $\sum \frac{0}{7}$ 㝵是 志总嵒

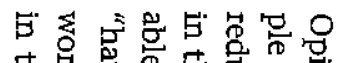

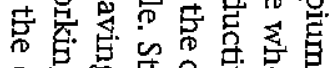

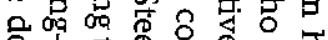

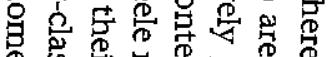

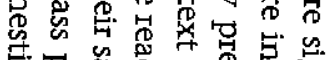

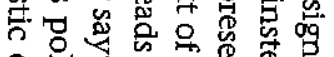

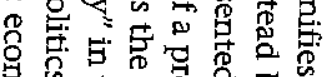

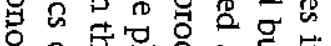

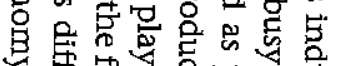

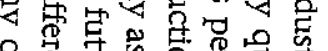

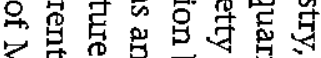

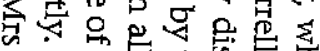

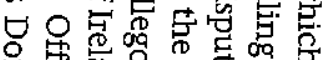

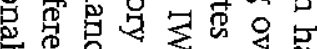
它这品要思

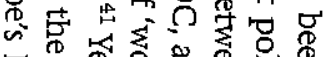

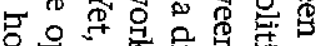

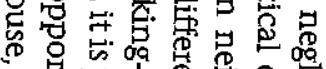

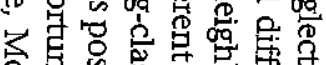

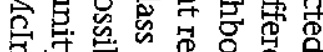

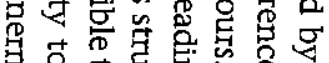

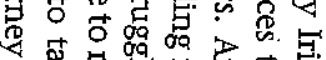

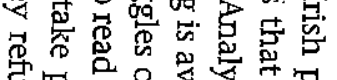

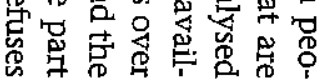

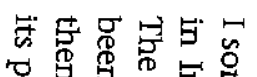
总总家 尊总总宫官

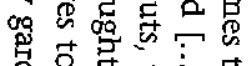

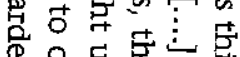
兽焉总心究

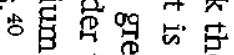

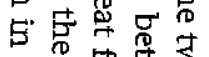

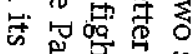

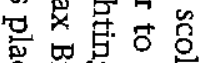

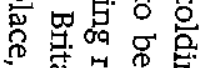

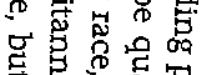
范贾

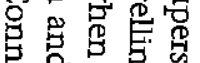
总悬学范 $+\mathrm{n}^{2}$ 点骂査葛

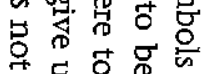

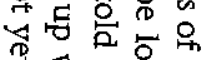

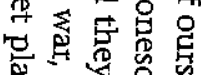
的员兽

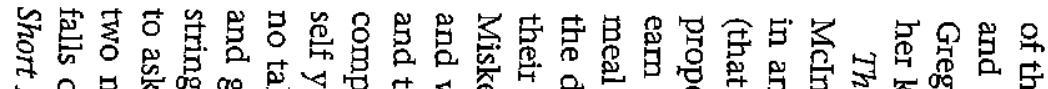

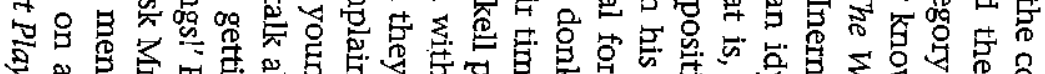

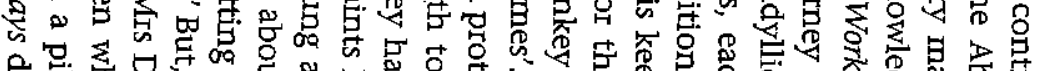

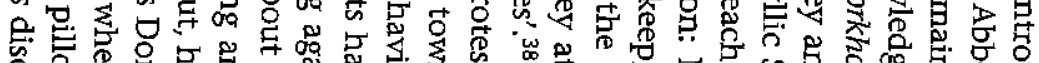

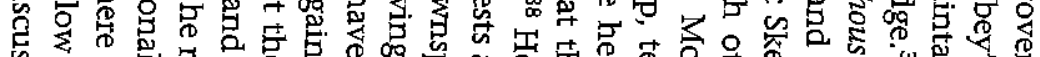

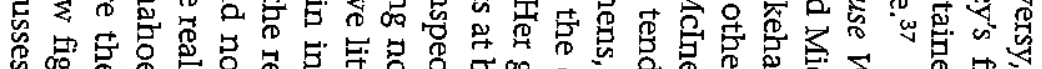

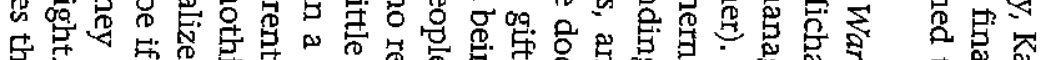

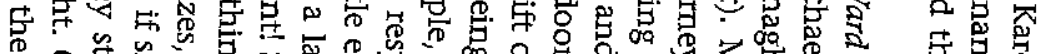

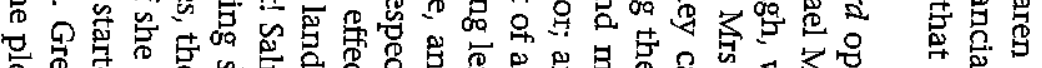

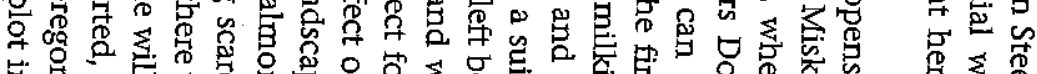

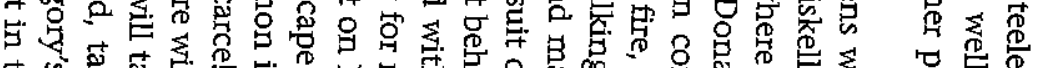

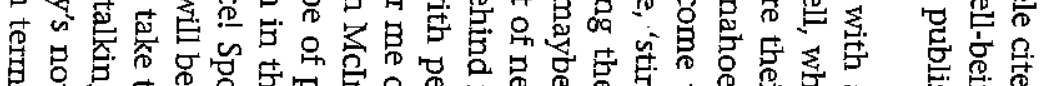

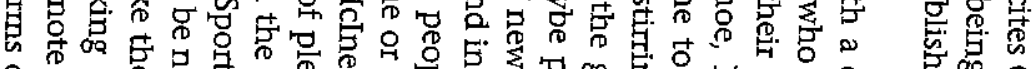

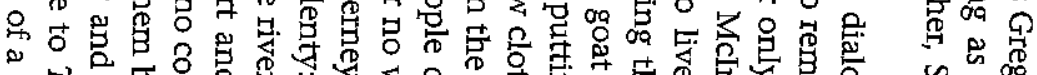

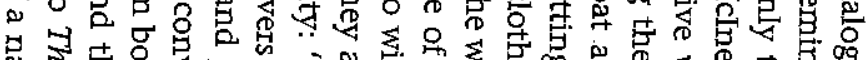

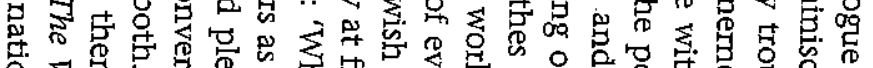

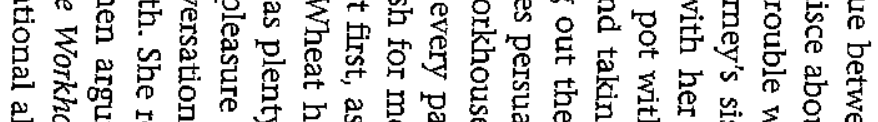

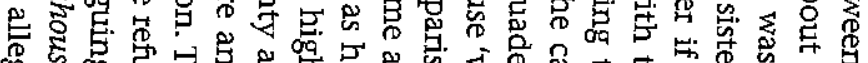

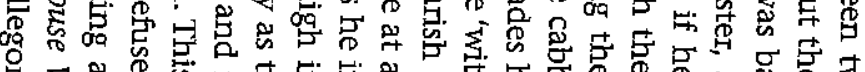

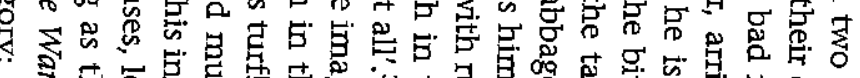

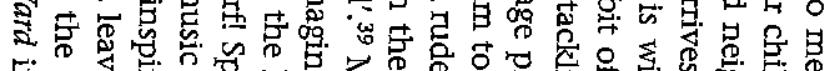

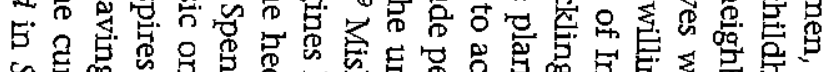

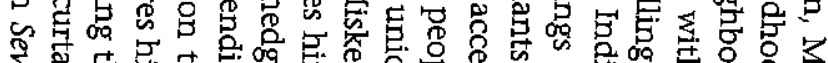

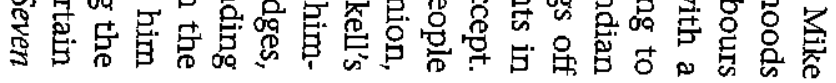

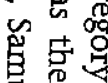

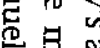

为

品

至泀

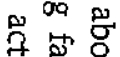

蛋苨总 $\leq$ $\stackrel{9}{9}$ 总憵总 


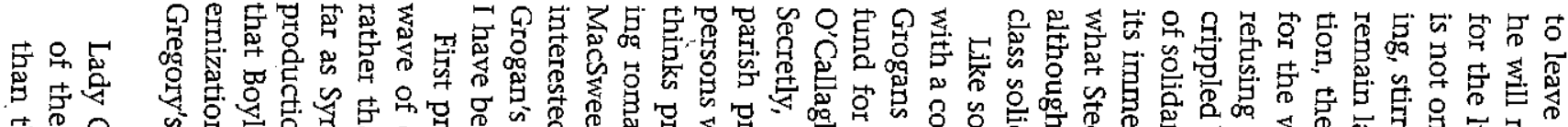

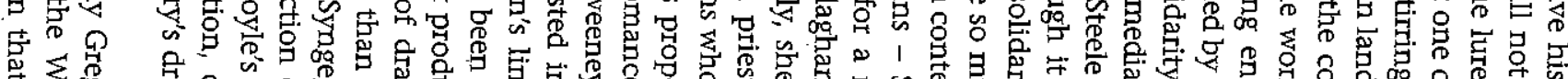

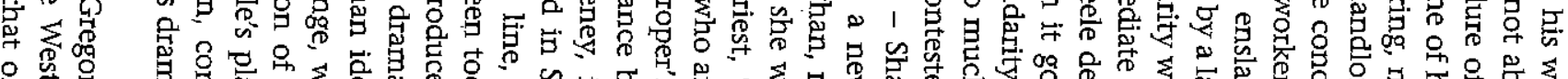

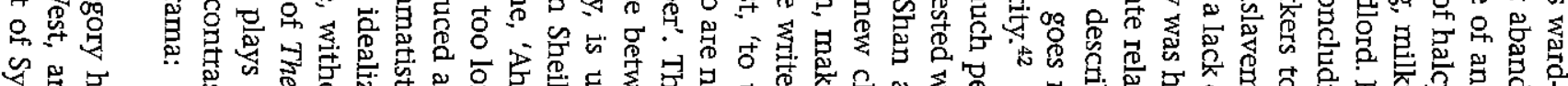
宲品 今. 考

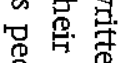
总客 空通

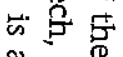
窟容

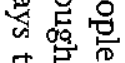
声说 S. 它它 空员

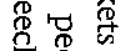
色愛

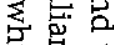

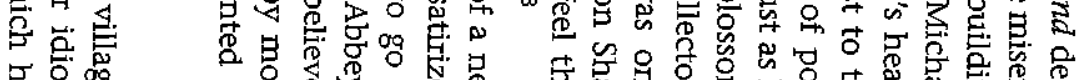

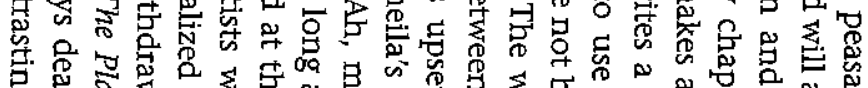

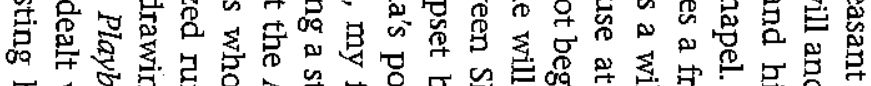

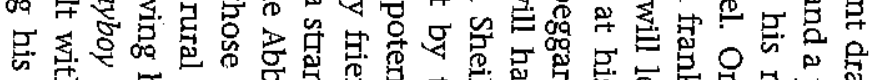

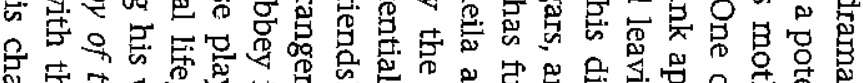

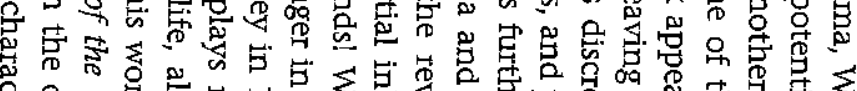

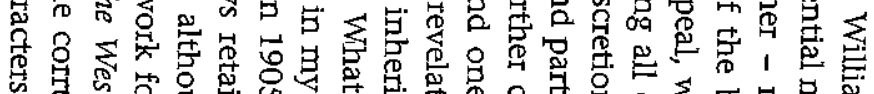

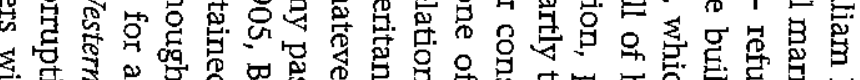

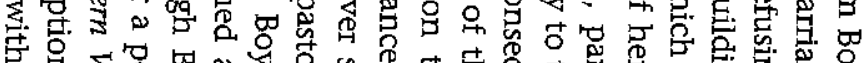

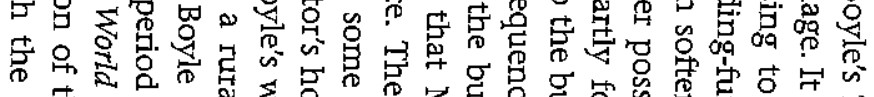

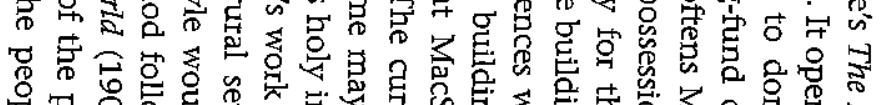

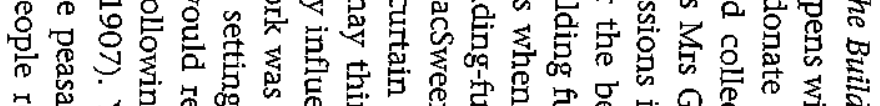

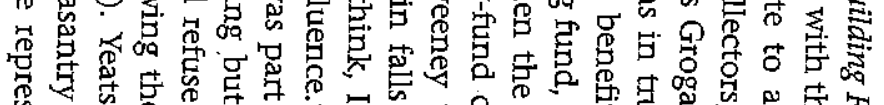

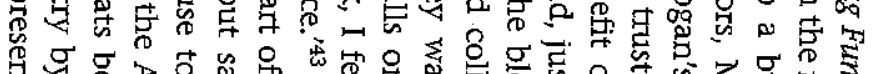

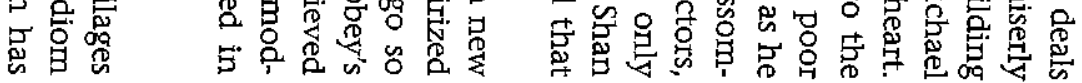

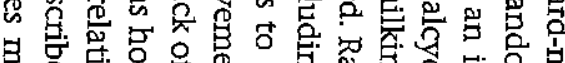

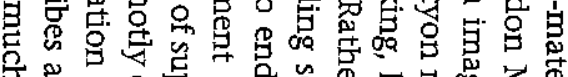

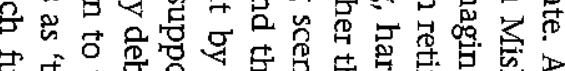

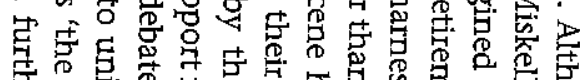

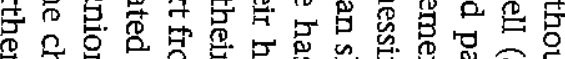

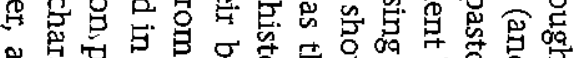

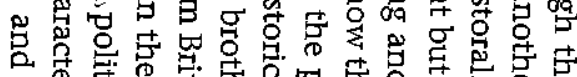

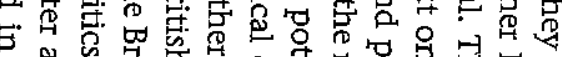

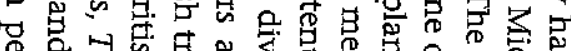

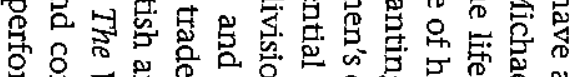

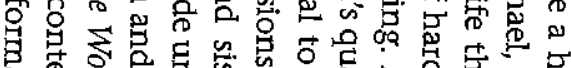

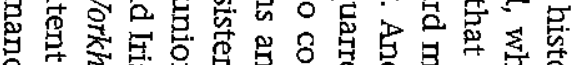

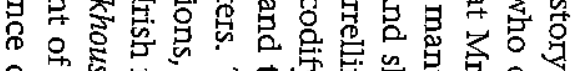

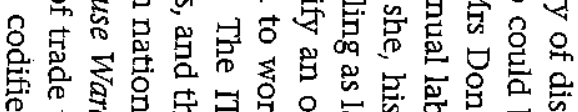

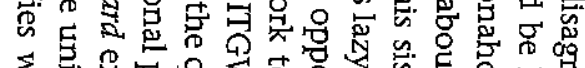

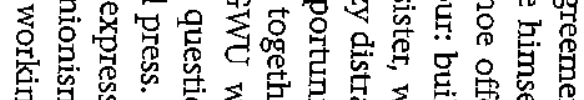

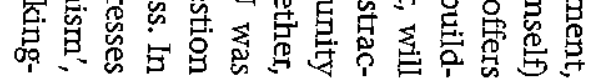

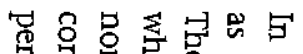

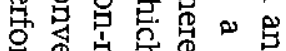

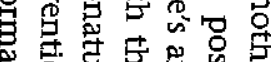

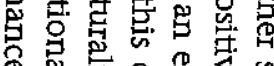

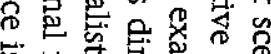

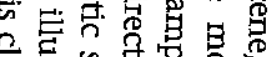

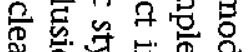

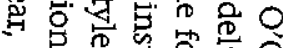

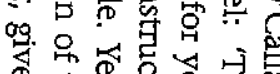

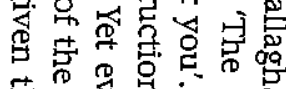

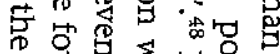

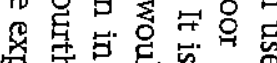
$\Rightarrow$ p

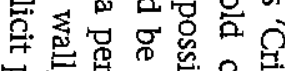

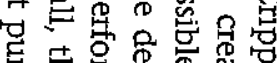

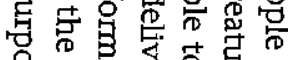

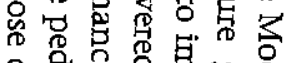

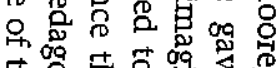

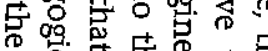

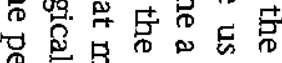
象念总总灾气

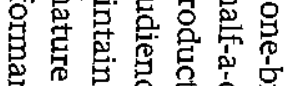

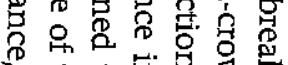

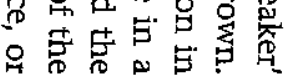

吅是占辈

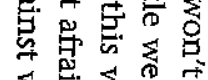

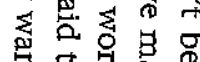

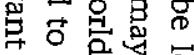
届定

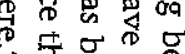

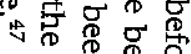

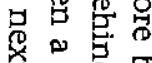
$\rightarrow 2$ :

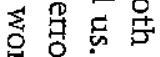
要品

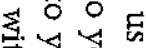
声导怘 年

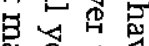

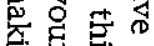

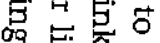
它草 0 过若 总忠宽 骂畋宫

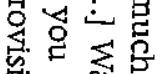
谷㫷号

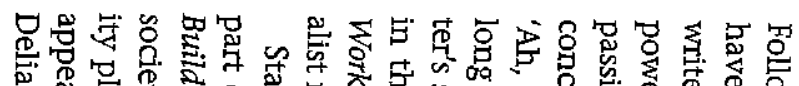

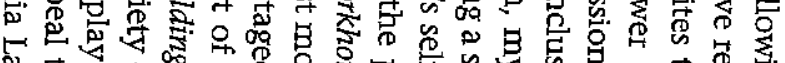

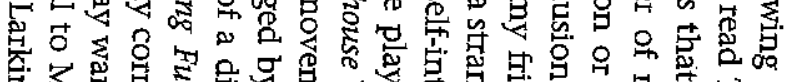

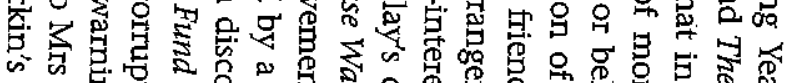

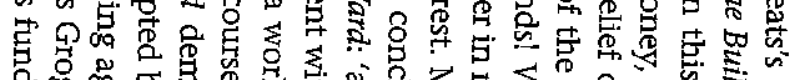

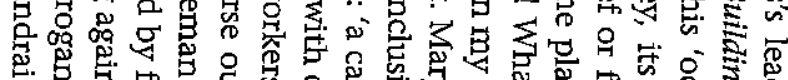

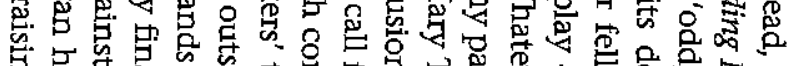

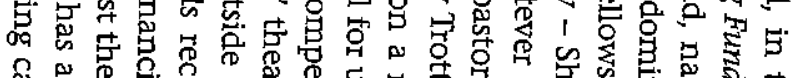

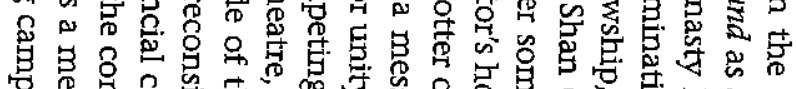

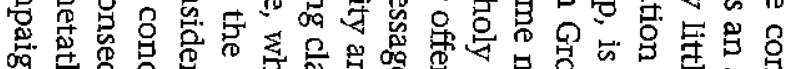

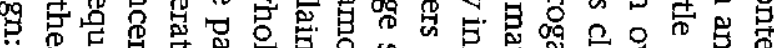

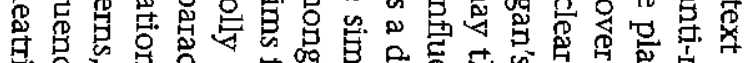

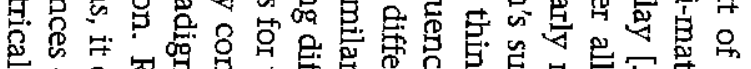

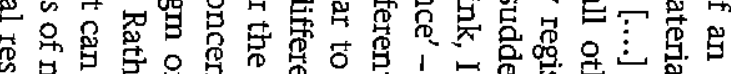

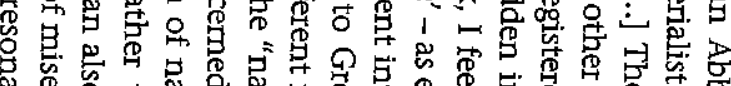

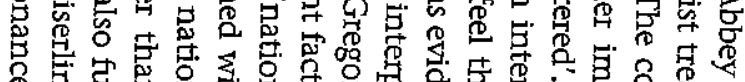

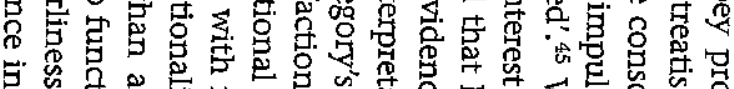

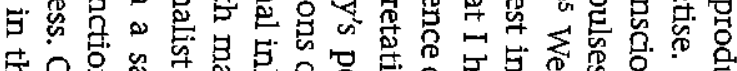

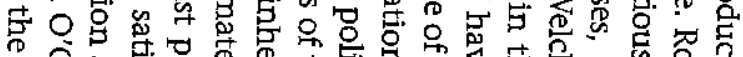

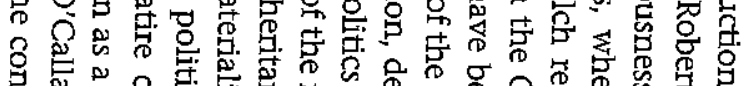

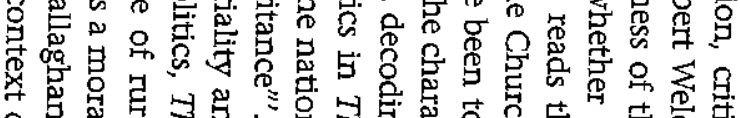

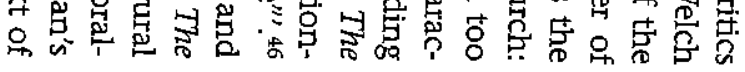

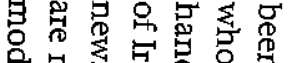

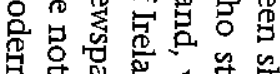

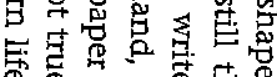

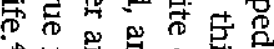

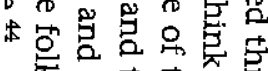
富京宫宫

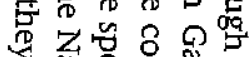

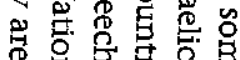

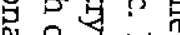

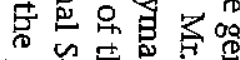

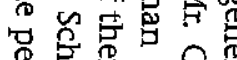

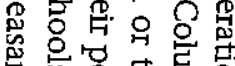

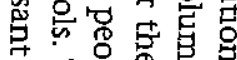

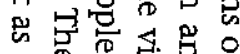

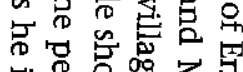

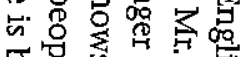

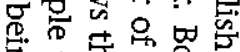

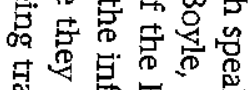

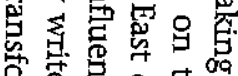

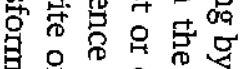

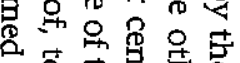

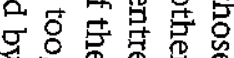




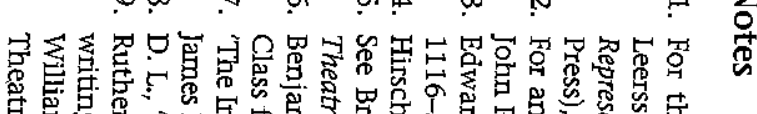

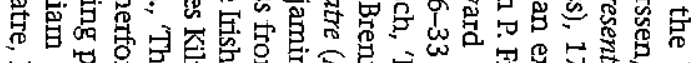

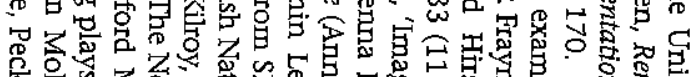

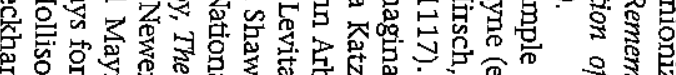

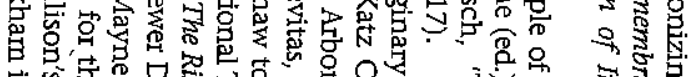

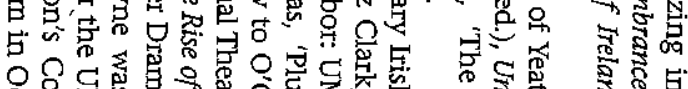

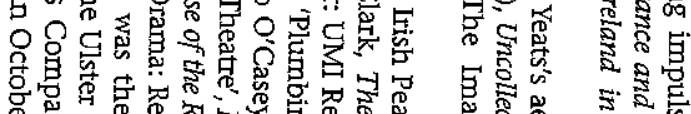

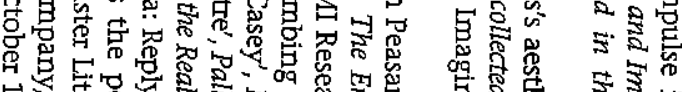

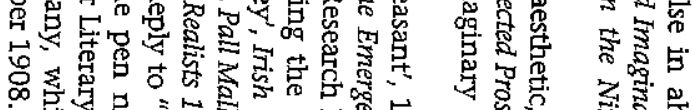

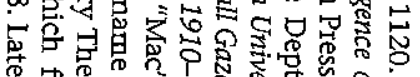

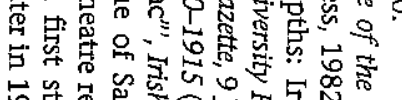

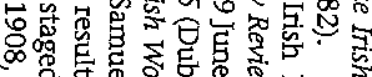

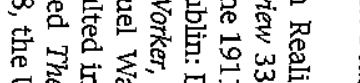

Con

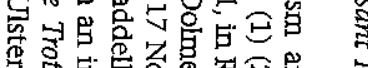

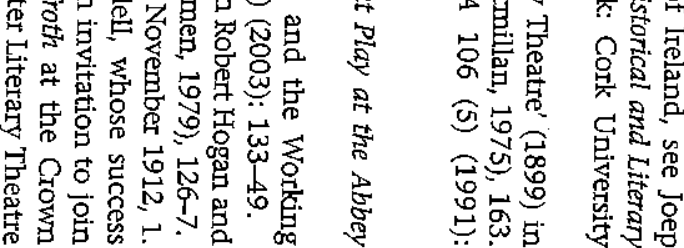

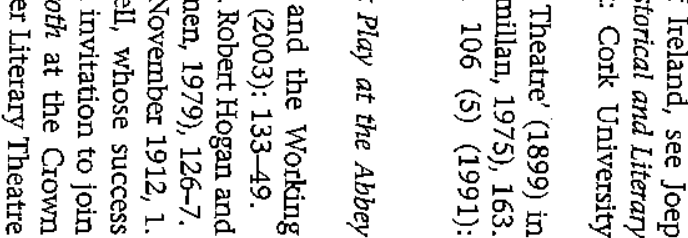

尊

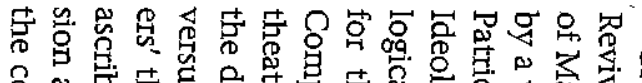

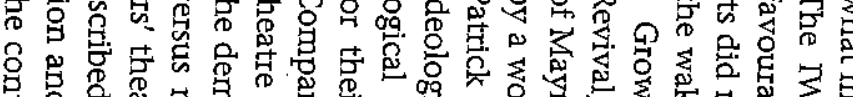

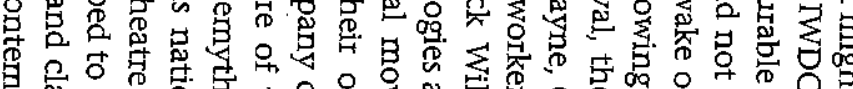

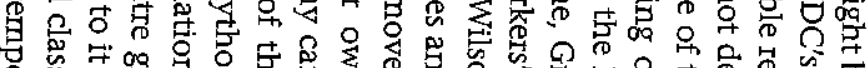

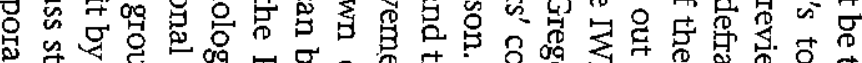

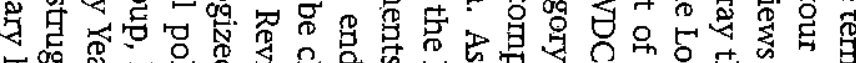

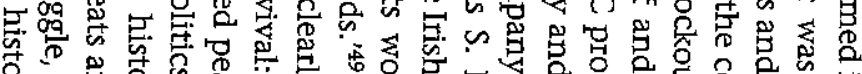

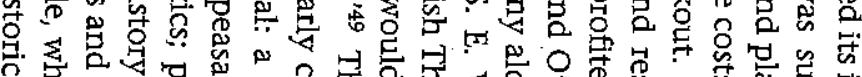

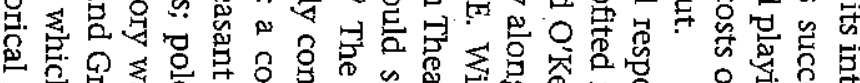

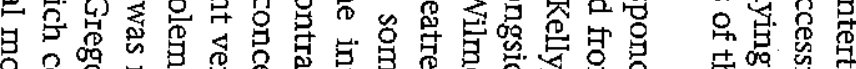

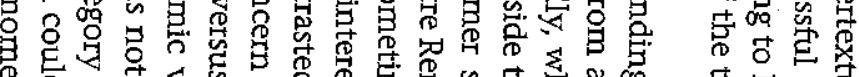

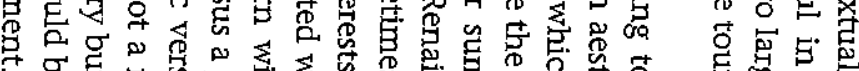

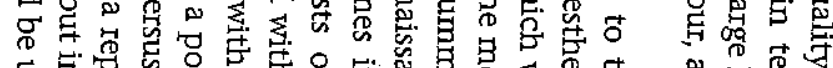

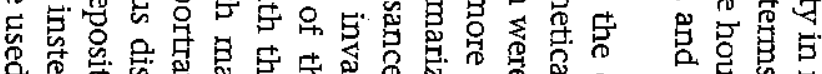

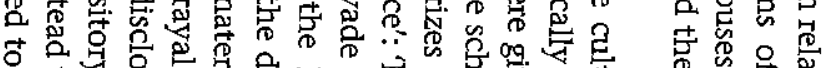

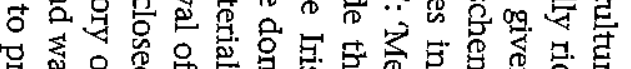

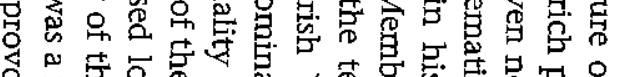

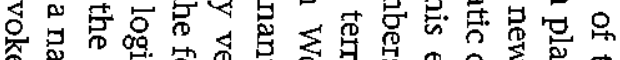

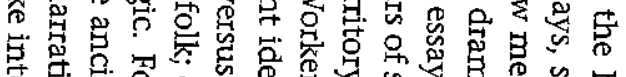

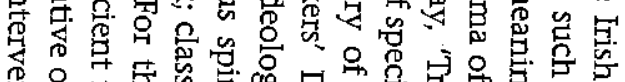

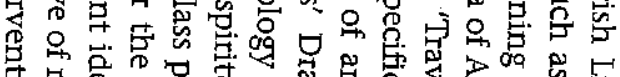

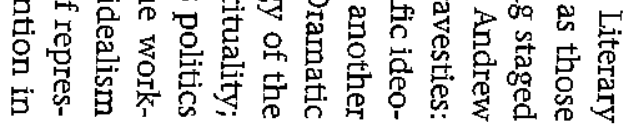

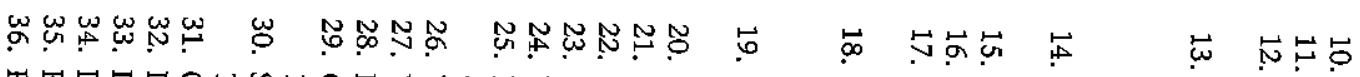

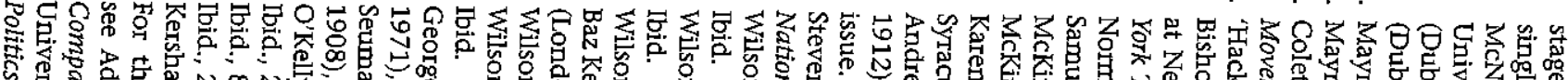

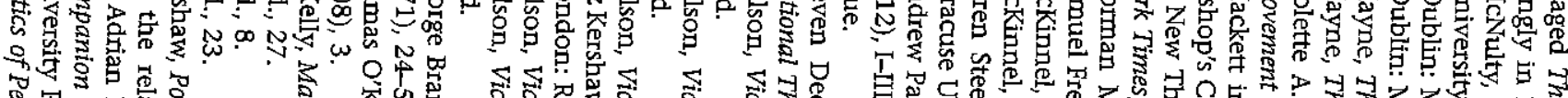

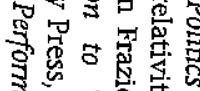

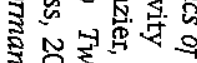

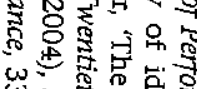

w.

象 象骂

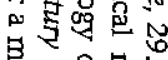

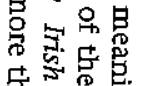

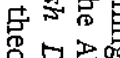

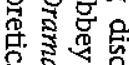

命宽

总总点 5

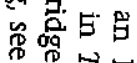

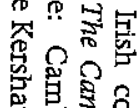

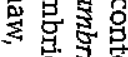

공명

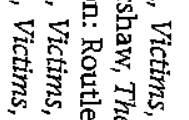

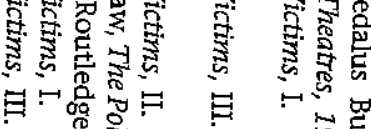

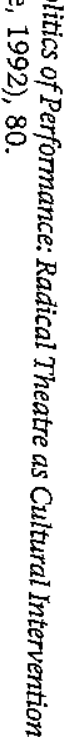

品密

总

tit.

结部

ํㅗㄹ

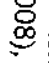

焉

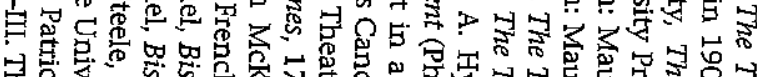

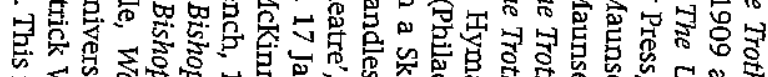

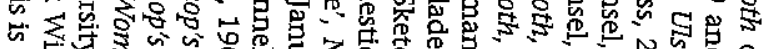

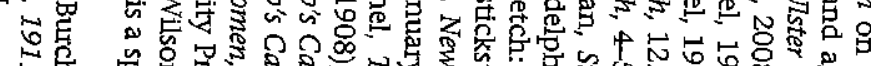

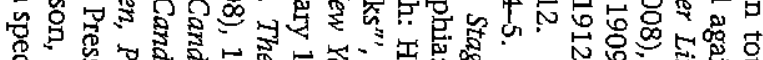

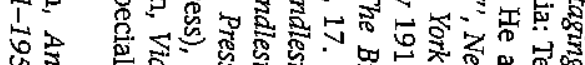

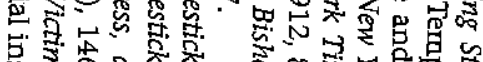

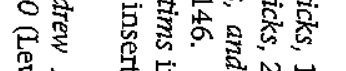

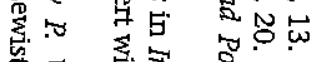

害

窟

更

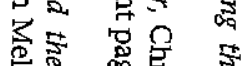

总

焉

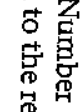

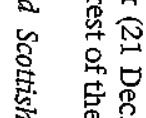

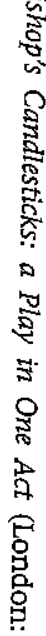

مै

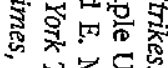

我象电

空志思

品易

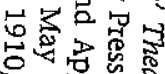

ㄴㅇㅠ.

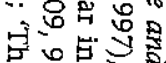

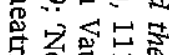

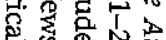

制星

盯造

置5

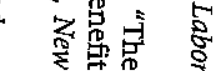

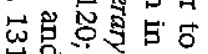

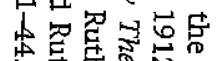

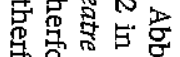

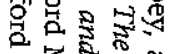

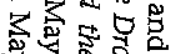

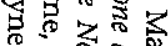

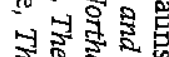

क

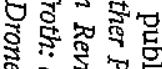

D

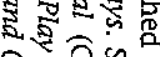

웧유.

ร

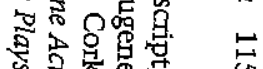




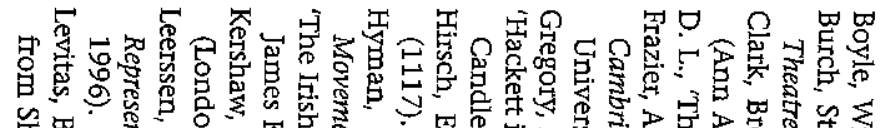

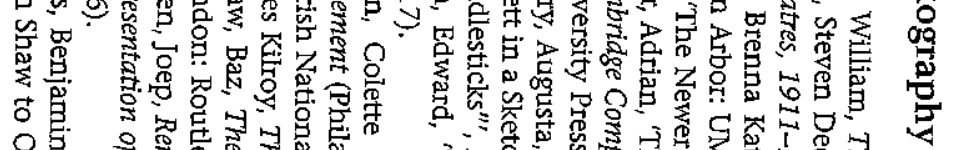

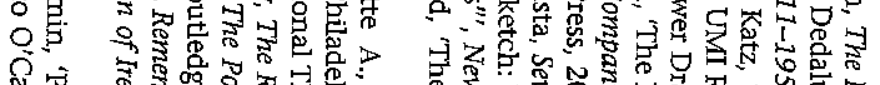

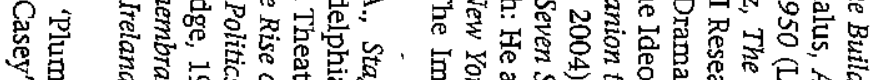

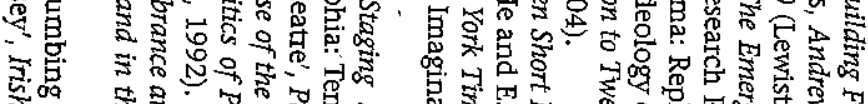

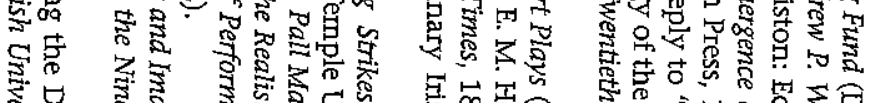

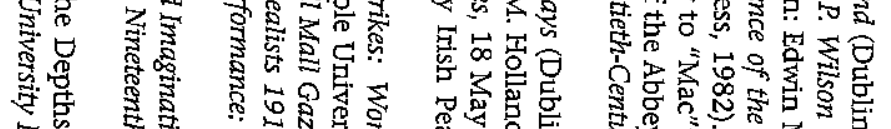
对 专

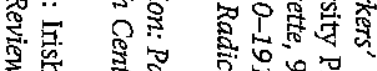

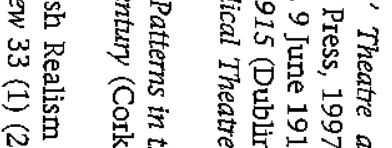

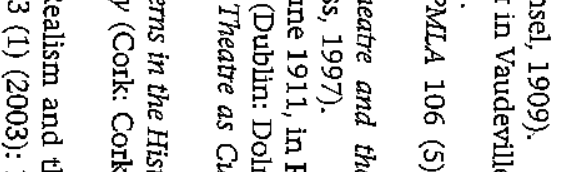

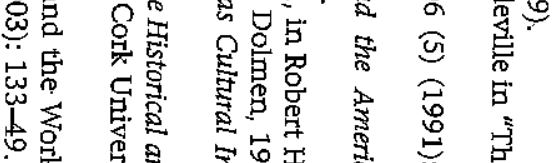

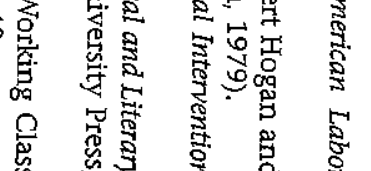

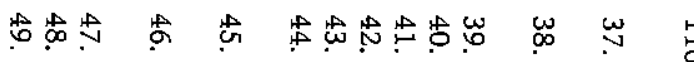

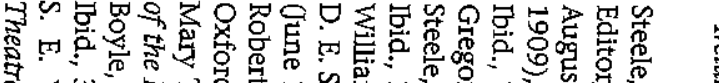

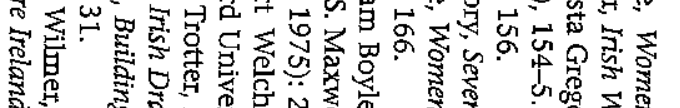

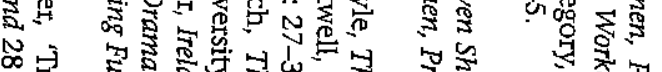

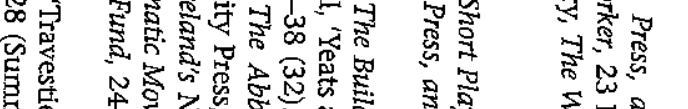
究 s.

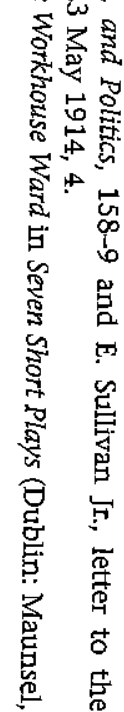

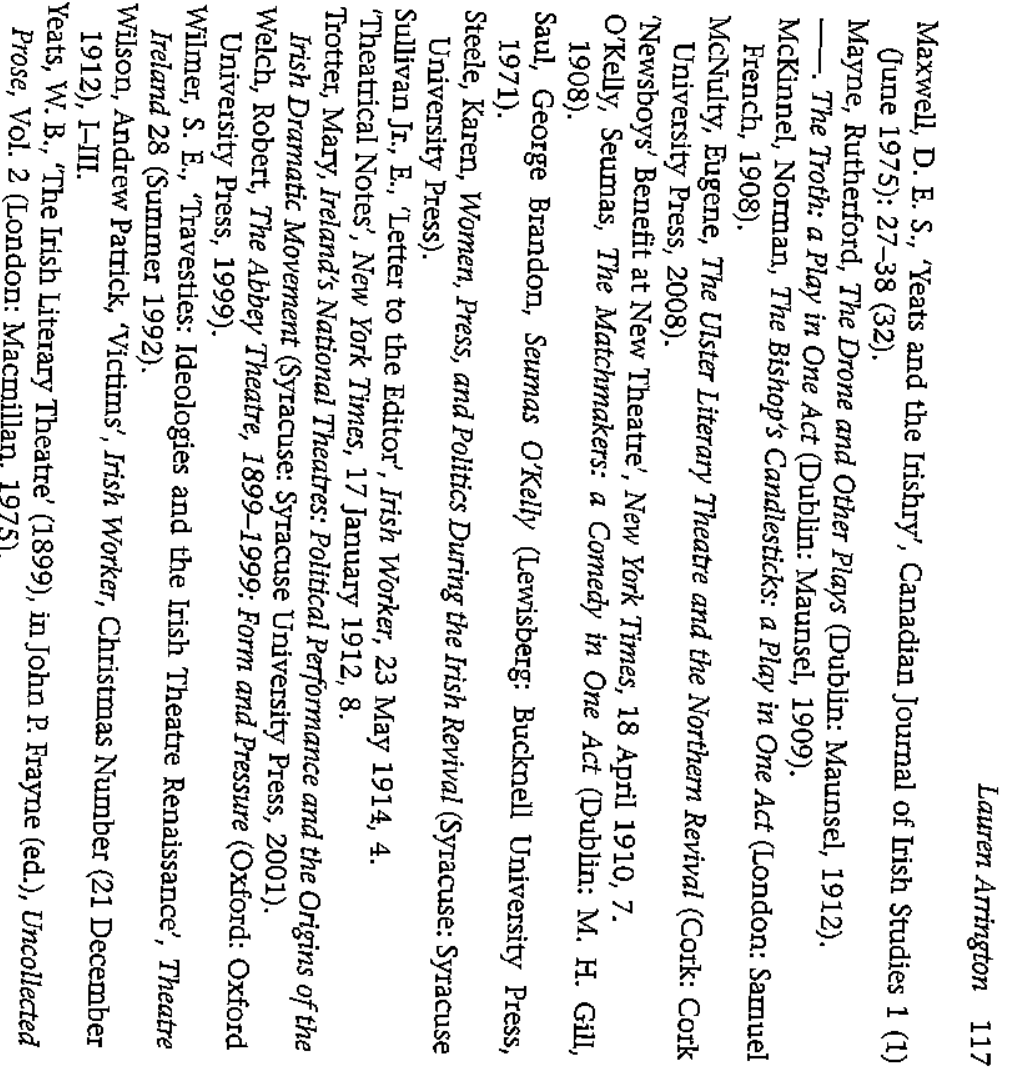

